\title{
Estancamiento y desaliento del desarrollo productivo en la región agrícola del Valle de Mexicali, Baja California: un análisis tendencial
}

\begin{abstract}
JoséZavalaÁlvarez*
Resumen. El propósito de este artículo es mostrar las condiciones y tendencias del desarrollo productivo de la región agrícola del Valle de Mexicali, en Baja California, en el periodo 1983-2001, como medida de aproximación a las condiciones del desarrollo agrícola de la región. El propósito deriva de la hipótesis de que la actividad productiva agrícola en la región ha tenido un comportamiento errático con tendencia al estancamiento; en tal condición, el desarrollo productivo es el punto de partida para analizar el comportamiento de la actividad agrícola a través de la construcción de un análisis de tendencia de seis indicadores: superficie cosechada, rendimiento físico y económico de los principales cultivos, volumen y valor de la producción, y diversificación productiva. Para tal ejercicio analítico se hace uso de un par de instrumentos estadísticos: el análisis de series de tiempo con una función de regresión polinomial y la estimación del índice de concentración de Gini. Los resultados obtenidos permiten concluir el estancamiento y la evolución desalentadora, en general, de la actividad productiva agrícola de la región.

Palabras clave: desarrollo agrícola, desarrollo productivo, región, Mexicali, tendencias.
\end{abstract}

\begin{abstract}
A bstract. The intention of this article is to show the conditions and tendencies of productive development of the agricultural region in the Valley of Mexicali, Baja California, during the period between 1983 and 2001, as a means of approach to the conditions of the region's agricultural development. The objetivem is derived from the hypothesis that productive agricultural activity in the region has behaved erratically, showing a tendency toward stagnation. Under such circumstances, productive development is taken as the point of departure to analyze the behavior of agricultural activity through the construction of a tendency analysis using six indicators: harvested surface, physical and economic productivity of the principal crops, production volume and value, and productive diversification. In order to carry out this analytical exercise, two statistical instruments were used: time series analysis, with a polynomial regression function, and a Gini index estimation. The results obtained showed stagnation and a discouraging evolution, in general, of the region's productive agricultural activity.

Key words: agricultural development, productive development, region, Mexicali, tendency.
\end{abstract}

* Investigador de El Colegio de la Frontera Norte, Oficina regional de Mexicali, B.C. Correo electrónico: jza61@colef.mx 


\section{Introducción}

El Valle de Mexicali constituye una extensa región agrícola bajo riego, parte de un área binacional de cerca de 450 mil hectáreas. Localizado en el municipio del mismo nombre en el estado de Baja California, está situado sobre el delta del Río Colorado (Márquez de Romero, 1987: 72), el cual constituye la principal fuente de abastecimiento de agua. El río beneficia a poco más de 20 millones de habitantes, de los cuales 17.5 millones se ubican en siete estados deE.U. y el resto en México, fundamentalmente en Baja California (BANCOMER, 1976: 34,40). El valle de Mexicali constituye uno de los distritos de riego más grandes del país. ${ }^{1}$ En 1939 fue creado el Distrito de Riego número 014 por la extinta Comisión Nacional de Irrigación, explotándose inicialmente 170,000 hectáreas (SARH, 1976: 5); en la actualidad, son cerca de 208 mil hectáreas las que tienen derecho de uso de agua para riego agrícola.

La actividad agrícola llegó a Mexicali proveniente de Estados Unidos. En la actualidad, la producción aún tiene un alto grado de dependencia del mercado estadounidense, ya que la disponibilidad y consumo de un buen número de insumos y la venta de productos agrícolas tienen a ese país como origen y destino. Deigual manera, la disposición de tecnología y recursos financieros de origen extranjero han sido determinantes para el desarrollo agrícola de la región (Grijalva, 1978: 23, 28).

A semejanza del modo de producción estadounidense, la agricultura que se practica en esta región es de carácter eminentemente comercial, muy ligada a la exportación, sobretodo deal godón y hortaliza. Sus principales características son: su carácter intensivo que implica un alto grado de mecanización en las labores agrícolas; la utilización masiva de agroquímicos; una alta especialización productiva que se acerca más a la idea del monocultivo; mano de obra contratada prácticamente en su totalidad; y nula utilización de prácticas ecológicas

\footnotetext{
${ }^{1}$ Bajo del Río Bravo (Tamaulipas) con cerca de 286 mil hectáreas; el Valle del Río Fuerte (Sinaloa) con 267 mil hectáreas; el Valle del Yaqui (Sonora) con 260 mil hectáreas; y el Río Colorado (Mexicali en B.C. y San Luis Río Colorado, Sonora) con casi 208 mil hectáreas. Véase SARH (1976).
} 
de producción, como labores culturales (preparación, siembra, cultivo) para la conservación y mejoramiento de suelos, uso desmedido de pesticidas y fertilizantes fósiles e incipiente uso de fertilizantes orgánicos. A pesar de todo ello, tiene una escala de producción significativa en el contexto nacional (Pérez, 1988: 45-49).

El propósito de este artículo es mostrar las condiciones y tendencias del desarrollo productivo dela región agrícola del ValledeM exicali como medida de aproximación a las condiciones del desarrollo agrícola de la región. El desarrollo agrícola de una región puede entenderse como un proceso de mejoramiento de condiciones en las que se desarrollala actividad agrícola o su sistema productivo. Esteproceso, en el que participan sujetos sociales, se da diferencialmente en un espacio territorial y tiempo determinados a través de la utilización de recursos intra y extraterritoriales (Jiménez, 1999: 12). ${ }^{2}$

Este trabajo surge a partir de la hipótesis de que la actividad productiva agrícola en la región ha tenido un comportamiento errático con tendencia al estancamiento. Desde esta perspectiva, el desarrollo productivo resulta el punto de partida necesario para el ejercicio propuesto, de modo que se construyó un análisis de tendencia de seis indicadores: superficietotal cosechada en hectáreas, rendimiento físico y económico de siete de los principales cultivos en toneladas por hectárea y miles de pesos por hectárea respectivamente, volumen y valor total de la producción en toneladas y millones de pesos respectivamente, y diversificación productiva medida a través de un índice concentración -Índice de Concentración de Gini- anualizado, utilizando los datos de superficie cosechada y val or de la producción.

\section{Instrumentos metodológicos}

\section{A nálisis de tendencia}

Se utilizó un modelo de series de tiempo (sт), a partir de los val ores en el tiempo de los indicadores mencionados. Se construyó un análisis de

2 Dos excelentes y completas obras sobre teorías de desarrollo agrícola que pueden consultarse son: Eicher y Staatz (1991) y Vernon y Hayami (1989). 
tendencias utilizando como instrumento metodológico el análisis de regresión. La tendencia es la dirección general de una variable en el periodo de observación, es decir, el cambio a largo plazo de la media de la serie (Aguirre, 1994:3). Un modelo dásico para una sт supone que una serie $x_{1}, \ldots, x_{n}$ puede ser expresada como suma o producto de tres componentes: tendencia, estacionalidad y un término de error aleatorio (Arellano, 2001: 6). Existen tres modelos generalmente aceptados como buenas aproximaciones a las verdaderas relaciones entre los componentes de los datos observados, a saber:

$$
\begin{gathered}
\text { Aditivo: } X_{t}=T_{t}+E_{t}+A_{t} \\
\text { Multiplicativo: } X_{t}=T_{t} \cdot E_{t} \cdot A_{t} \\
\text { Mixto: } X_{t}=T_{t} \cdot E_{t}+A_{t}
\end{gathered}
$$

Donde:

$X_{t}=$ Serie observada en instantet

$\mathrm{T}_{\mathrm{t}}=$ Componente de tendencia

$\mathrm{E}_{\mathrm{t}}=$ Componente estacional

$A_{t}=$ Componentealeatoria (accidental)

Un modelo aditivo es adecuado cuando $E_{t}$ no depende de otras componentes, como $\mathrm{T}_{\mathrm{t}}$. Si, por el contrario, la estacionalidad varía con la tendencia, el modelo más adecuado es un modelo multiplicativo. En el caso de este estudio, debido a los datos agregados en años agrícolas, la estimación de la tendencia supone que el componente estacional -E- de la serie de tiempo en observación no está presente, lo que significa un modelo de st del tipo aditivo. En función de la definición de este modelo, el cálculo de la tendencia se lleva a cabo utilizando el método de ajuste de una función del tiempo a través de una función polinomial. En el caso de este estudio, se propone una función de grado seis debido a la necesidad de obtener mayor nivel de bondad -grado decorrespondencia entrelos valores estimados con los datos reales- por el carácter fluctuante de los datos de los diversos 
parámetros, es decir, para obtener un coeficiente de determinación $\mathrm{R}^{2}$ más alto. La expresión matemática de la función utilizada es:

$$
Y=B+C_{1} X+C_{2} X^{2}+C_{3} X^{3}+\ldots+C_{6} X^{6}
$$

Donde:

Y = Línea de tendencia (valores de X ajustados a la función)

$X=$ Valores dela serie observados

$\mathrm{B}=$ Componente al eatorio (constante)

$\mathrm{C}_{1} \ldots \mathrm{C}_{6}=$ Coeficientes constantes de $\mathrm{X}$

Para el cálculo del valor del coeficiente de determinación $\mathrm{R}^{2}$ se utiliza:

$$
\mathrm{R}^{2}=1-\frac{S S E}{S S T}
$$

Donde: SSE $=\sum\left(Y_{i}-\bar{Y}_{i}\right)^{2} \quad$ SST $=\left(\sum Y_{i}^{2}\right)-\frac{\left(\sum Y_{i}\right)^{2}}{n}$

Diversificación o especialización: Índice de Concentración de Gini

Desde el punto de vista meramente estadístico, la concentración tiene que ver con la manera como se reparte el total de una variable entre un conjunto de observaciones o unidades. Es decir, se define en términos de la distribución del monto total entre el número de unidades. Al tamaño de la variable se le denomina nivel de la variable. La diferenciación entre el nivel y su repartición -es decir, el grado de desigualdad- resulta fundamental en tanto proporciona elementos clave para interpretar con precisión los resultados que arrojan las medidas estadísticas (Cortés y Rubalcava, 1984:13-14). Ello nos permite hacer aseveraciones respecto a posibles escenarios consecuentes.

Es importante conocer el grado de diversificación, o de concentración -como idea contraria-, de la producción agrícola con el propósito de acercarnos a la realidad de la especialización productiva de 
la región. Este dato resulta de utilidad pues tiene que ver con la vulnerabilidad que puede tener la estructura productiva frente al mercado debido a la alta producción de pocos cultivos. En teoría, la diversificación productiva en mayor grado tendría un efecto positivo en la región en tanto su desarrollo o progreso no dependería de pocos cultivos; de igual manera, cada grupo de productores o incluso el productor en lo individual tendría mayor posibilidad de progreso si su actividad tiene una mayor diversificación, pues de este modo, si alguno de los cultivos enfrenta condiciones adversas en el mercado, otros sostendrían la economía de tales grupos sociales, productores y región.

Una medida de concentración constituye una evaluación de resultados de una política que alienta la diversificación. Conociendo la evolución de la diversificación puede conocerse la efectividad de tal política. Uno de los estimadores más utilizados para medir concentración es el coeficiente conocido como índice de concentración de Gini, que se deriva como resumen de las discrepancias con respecto a la norma democrática -entendida como criterio de distribución equitativa de un total entre n elementos- representada por la media aritmética, aunque no se exprese formalmente en términos de un promedio. El coeficiente de Gini se interpreta entonces como una medida que reúne en un solo val or las comparaciones entre los val ores de variable que corresponden al universo de pares de observaciones (Cortés y Rubalcava, 1984: 47). Este índice se diferencia de otras técnicas para medir la desigualdad en la manera como formaliza la norma democrática: "en lugar de representarla a través del promedio, establece la distribución teórica que debería tener la variable si se repartiese por igual entre todas la unidades". De esta manera, "la idea central que orienta la construcción del índice consiste en comparar dos distribuciones: la empírica y la que se deriva de la norma democrática", donde "la comparación se hace operativa a través de las discrepancias entre las frecuencias relativas acumuladas de la variable en ambas distribuciones. En el caso de datos no agrupados, el análisis arrojaría bajo una distribución equitativa que a un dato que represente mayor proporción del total le correspondiese una mayor proporción de la 
variable" (Cortés y Rubalcava, 1984: 49-50). La expresión matemática del índice de Gini es la siguiente:

$$
G=\frac{\sum_{i=1}^{n-1}\left(P_{i}-Q_{i}\right)}{\sum_{i=1}^{n-1} P_{i}}
$$

Donde:

$\mathrm{G}=$ Índice de concentración de Gini

$P_{i}=$ Proporción acumulada que cada observación $p_{i}$ representa dentro del total

$Q_{i}=$ Proporción acumulada que cada observación posee de la variableq

$\mathrm{n}=$ Número de observaciones de la variable $\mathrm{q}_{\mathrm{i}}$

$\mathrm{p}_{\mathrm{i}}=$ Proporción que una observación representa en el número total deobservaciones

$q_{i}=$ Proporción que el valor de cada observación de la variable re presenta del valor total

El índice de Gini alcanza un valor mínimo de cero siempre que todo $\mathrm{iP}_{\mathrm{i}}=\mathrm{Q}_{i}$; en otros términos, este coeficiente es nulo cuando la variable se distribuye democráticamente entre todas las unidades. Su valor máximo es uno y se llega a él cuando $Q_{1}=Q_{2} \ldots Q_{n-1}$, es decir, $G$ será igual a la unidad si el valor total de la variable le corresponde sólo a una de las observaciones. Para efectos del presente trabajo, superficie cosechada -en hectáreas- y val or de la producción -en millones de pesos- de cada uno de los cultivos que las cédulas anuales comprenden, serán las unidades de observación utilizadas. El número de observaciones depende del número de cultivos que se establecieron en cada año agrícola, y se estimará el índice para los años 1983 al 2001 con el objeto de observar los cambios en la diversificación productiva durante este periodo. 


\section{Análisis tendencial del desarrollo productivo}

Superficie cosechada

El análisis de tendencia del comportamiento de la superficie cosechada en el Valle de Mexicali presenta, en general, una perspectiva negativa (figura 1). Sin embargo, se distinguen dos niveles: antes de 1987 la superficie cosechada llegó a superar las 200 mil hectáreas (cuadro 1), lo cual se explica tanto por el carácter climático como por el efecto de políticas agrícolas nacionales. En el periodo de 1984 a 1987 se presentaron en la región excedentes de agua debido a los deshielos delas partes altas en Estados Unidos; los volúmenes de agua conducidos por el Río Colorado hasta el Valle de Mexicali provocaron inundaciones en algunas zonas, pero también la disponibilidad hidráulica para mayores superficies de siembra y dobles cultivos. Por otro lado, las políticas agrícolas de aliento a la producción pecuaria de la década delos ochenta a través de créditosy programas deapoyo ala ganadería estimularon la siembra de mayores superficies de forrajes -como el caso del Rye Grass y el Sorgo Forrajero- como insumos para grandes explotaciones ganaderas en la región (Rechy, 2000: 49-56).

\section{Figura 1.}

Tendencia de la superficie cosechada total en el Valle de M exicali (hectáreas)

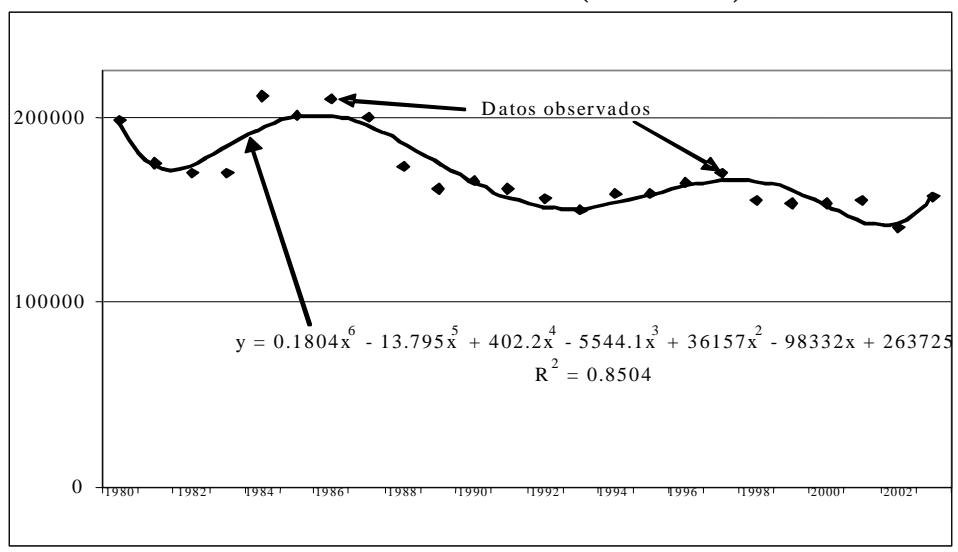

Fuente: Cuadro 1. 


\section{Cuadro 1.}

Superficie cosechada en el Valle de M exicali (hectáreas)

\begin{tabular}{|c|c|c|c|c|c|c|c|c|c|c|c|c|c|c|c|c|c|c|c|c|c|c|c|c|}
\hline & 1980 & 1981 & 1982 & 1983 & 1984 & 1985 & 1986 & 1987 & 1988 & 1989 & 1990 & 1991 & 1992 & 1993 & 1994 & 1995 & 1996 & 1997 & 1998 & 1999 & 2000 & 2001 & 2002 & 2003 \\
\hline Acelga & & & & & & & & & & & & & & & & 62 & 38 & 81 & & 8 & 20 & 5 & & \\
\hline Ajo & 296 & 262 & 215 & 106 & 169 & 145 & 114 & 95 & 106 & 92 & 15 & & 155 & 153 & 235 & 338 & 237 & 139 & 341 & 584 & 380 & 431 & 450 & 448 \\
\hline Ajonjolí & 9,573 & 3,349 & 1,063 & 1,054 & 10,514 & 17,754 & 19,507 & 13,009 & 4,013 & 2,209 & 7,231 & & & 8 & & & & & & & & & & \\
\hline $\begin{array}{l}\text { Alcachofa } \\
\text { Alfalfa }\end{array}$ & & & & & & & & & & & & & 8 & & & & & & & & & & & \\
\hline Alfalfa & $\begin{array}{l}13,120 \\
65961\end{array}$ & 13,852 & 13,624 & $\begin{array}{l}13,953 \\
35372\end{array}$ & $\begin{array}{l}14,174 \\
64,852\end{array}$ & $\begin{array}{l}16,356 \\
38,238\end{array}$ & $\begin{array}{l}17,506 \\
34,483\end{array}$ & $\begin{array}{l}12,429 \\
36,550\end{array}$ & $\begin{array}{l}14,202 \\
55,125\end{array}$ & $\begin{array}{l}17,753 \\
37,212\end{array}$ & $\begin{array}{l}15,095 \\
40,345\end{array}$ & & 18,432 & 16,198 & 17,303 & 20,757 & 18,717 & 17,832 & $\begin{array}{l}19,790 \\
\end{array}$ & 20,837 & 24,021 & $\begin{array}{l}25,975 \\
237725\end{array}$ & $\begin{array}{l}26,969 \\
72713\end{array}$ & $\begin{array}{l}28,305 \\
13,327\end{array}$ \\
\hline $\begin{array}{l}\text { Algodón } \\
\text { Apio }\end{array}$ & 65,961 & 70,014 & 36,707 & 35,372 & & & & 36,550 & 55,125 & 37,212 & 40,345 & & 17,814 & $\begin{array}{l}649 \\
182\end{array}$ & $\begin{array}{r}9,663 \\
136\end{array}$ & $\begin{array}{r}26,806 \\
147\end{array}$ & $\begin{array}{r}43,276 \\
108\end{array}$ & $\begin{array}{r}33,822 \\
16\end{array}$ & $\begin{array}{r}43,715 \\
144\end{array}$ & $\begin{array}{r}35,115 \\
156\end{array}$ & $\begin{array}{r}15,076 \\
60\end{array}$ & $\begin{array}{r}23,725 \\
82\end{array}$ & $\begin{array}{r}12,713 \\
40\end{array}$ & $\begin{array}{r}13,327 \\
40\end{array}$ \\
\hline $\begin{array}{l}\text { A vena } \\
\text { forr. verde } \\
\text { Berenjena }\end{array}$ & & & & & & & & & & & 1,251 & & $\begin{array}{r}944 \\
8\end{array}$ & 339 & 430 & 978 & 678 & 1,147 & 1,284 & 747 & 595 & 1,081 & 992 & 1,192 \\
\hline Betabel & & & & & & & & & & & & & 21 & 23 & 100 & 76 & 41 & 43 & 49 & 40 & 35 & 41 & 8 & 39 \\
\hline Boichoi & & & & & & & & & & & & & 24 & 63 & 24 & 12 & 48 & 11 & 2 & 1 & 15 & 7 & 5 & \\
\hline Brócoli & 4 & 73 & & 14 & 114 & 164 & 109 & 133 & 230 & 315 & 201 & & 399 & 202 & 372 & 51 & 308 & 233 & 238 & 557 & 367 & 380 & 116 & $\begin{array}{r}189 \\
2\end{array}$ \\
\hline Cacahuate & & & & & & & & & & & & & & & & & & & & 31 & & & & $\begin{array}{r}2 \\
153\end{array}$ \\
\hline Calabacita & & & & & & 119 & & & & & 158 & & 110 & 126 & 105 & 112 & 262 & 115 & 78 & 139 & 119 & 159 & 121 & 153 \\
\hline $\begin{array}{l}\text { Calabaza } \\
\text { Canola }\end{array}$ & & & & & & & & & & & & & 48 & 3 & & & & & & 184 & 2 & 0 & & \\
\hline Cártamo & 3,793 & 2,084 & 1,743 & 1,737 & 2,154 & 1,126 & 1,512 & 3,581 & 2,266 & 4,260 & 4,125 & & 1,545 & 3,911 & 4,399 & 2,230 & 5,945 & 2,241 & 648 & 4,972 & 3,382 & 774 & 1,493 & 2,898 \\
\hline Cebada & 22,604 & 16,087 & 19,612 & 15,199 & 8,773 & 6,875 & 10,199 & 8,833 & 10,130 & 8,203 & 8,398 & & 1,206 & 468 & 427 & 661 & 366 & 429 & 350 & 192 & 248 & 1,281 & 2,256 & 2,834 \\
\hline Cebolla & 263 & 161 & 242 & 93 & 110 & 77 & 144 & 118 & 245 & 418 & 366 & & 797 & 426 & 448 & 334 & 338 & 254 & 328 & 797 & 401 & 376 & 153 & 125 \\
\hline Cebollín & 1,667 & 1,372 & 936 & 1,669 & 1,279 & 2,108 & 1,984 & 2,201 & 3,115 & 4,845 & 2,778 & & 3,543 & 3,912 & 3,924 & 3,337 & 3,848 & 4,926 & 4,737 & 5,178 & 3,769 & 4,498 & 4,273 & 3,721 \\
\hline $\begin{array}{l}\text { Chard } \\
\text { Chícharo }\end{array}$ & & & & & & & & & & & & & & 5 & 4 & & & & & & & & & 6 \\
\hline $\begin{array}{l}\text { Chícharo } \\
\text { Chile verde }\end{array}$ & & & & & & & & & & & & & $\begin{array}{l}20 \\
55\end{array}$ & & 24 & 47 & 63 & 62 & 53 & $\begin{array}{r}5 \\
69\end{array}$ & $\begin{array}{l}35 \\
95\end{array}$ & 109 & 36 & $\begin{array}{r}6 \\
36\end{array}$ \\
\hline $\begin{array}{l}\text { Chile verde } \\
\text { Cilantro }\end{array}$ & & & & & & & & & & & & & $\begin{array}{l}55 \\
64\end{array}$ & $\begin{array}{r}21 \\
130\end{array}$ & $\begin{array}{r}24 \\
166\end{array}$ & $\begin{array}{r}41 \\
125\end{array}$ & $\begin{array}{l}05 \\
178\end{array}$ & 369 & 336 & $\begin{array}{r}09 \\
492\end{array}$ & $\begin{array}{r}95 \\
601\end{array}$ & $\begin{array}{l}109 \\
717\end{array}$ & $\begin{array}{r}30 \\
604\end{array}$ & 440 \\
\hline Col & & & & & & & & & & & & & 59 & 124 & 153 & 93 & 106 & 45 & 107 & 138 & 148 & 45 & 17 & 20 \\
\hline Coliflor & & & & & & & & & & & & & 10 & & 57 & 44 & 58 & 60 & 10 & 46 & 76 & 15 & 64 & 34 \\
\hline Cominos & & & & & & & & & & & & & & & & & 1 & & & & & & & \\
\hline Daikon & & & & & & & & & & & & & 14 & 10 & 10 & & & & & 55 & & & & 6 \\
\hline Ejote & & & & & & & & & & & & & 11 & 15 & 17 & & & 5 & 30 & 44 & 83 & 16 & & 16 \\
\hline Espárrago & 1,892 & 1,641 & 1,484 & 1,532 & 1,816 & 2,275 & 2,063 & 2,867 & 2,713 & 2,902 & 3,099 & & 3,016 & 2,529 & 2,015 & 1,678 & 1,757 & 1,914 & 1,844 & 1,844 & 2,005 & 1,988 & 2,726 & 1,984 \\
\hline Espinaca & 98 & 50 & 57 & 42 & 11 & 47 & 75 & 146 & 95 & 158 & 183 & & 157 & 77 & 163 & 92 & 66 & 79 & 30 & 61 & 46 & 106 & 91 & 109 \\
\hline Eucalipto & & & & & & & & & & & & & & & & 8 & 11 & 11 & 11 & 11 & 11 & 14 & 19 & 19 \\
\hline
\end{tabular}

(Continúa) 


\section{Cuadro 1 (continuación)}

\begin{tabular}{|c|c|c|c|c|c|c|c|c|c|c|c|c|c|c|c|c|c|c|c|c|c|c|c|c|}
\hline & 1980 & 1981 & 1982 & 1983 & 1984 & 1985 & 1986 & 1987 & 1988 & 1989 & 1990 & 1991 & 1992 & 1993 & 1994 & 1995 & 1996 & 1997 & 1998 & 1999 & 2000 & 2001 & 2002 & 2003 \\
\hline Flor & & & & & & & & & & & & & 34 & & & 32 & 10 & & & & & & & \\
\hline Fresa & & & & & & & & & & & & & & & & & & & & & & & & 4 \\
\hline Frijol & & & & & & & & & & & & & 8 & & & & & & & & & & 88 & 35 \\
\hline Girasol & & & & & & & & & & & & & & & & & & & & 22 & & & & \\
\hline Haba & & & & & & & & & & & & & 20 & & & & & & & & & & & \\
\hline Higuera & & & & & & & & & & & & & & 5 & & & & 6 & 6 & 6 & 6 & & & \\
\hline Hortalizas & & & & & & & & & & & & & 164 & & & & & & & & & & & \\
\hline Gay-lan & & & & & & & & & & & & & 20 & & & & 18 & & & & & & & \\
\hline Jitomate & & & & & & & & & & & & & 87 & 59 & 89 & 14 & 72 & 41 & 21 & 14 & 23 & 39 & 17 & 30 \\
\hline Kenaf & & & & & & & & & & & & & 2 & & & & & & & & & & & \\
\hline Kai-Iaan & & & & & & & & & & & & & & & & & & & 10 & 45 & 5 & 45 & & \\
\hline Kale & & & & & & & & & & & & & 33 & 30 & 24 & 35 & 18 & 8 & 34 & 24 & 68 & 78 & 56 & 14 \\
\hline Kohlrabi & & & & & & & & & & & & & & 5 & 4 & 20 & 15 & 40 & & 35 & 10 & 32 & & \\
\hline Lechuga & 433 & 320 & 202 & 282 & 498 & 667 & 438 & 497 & 523 & 715 & 455 & & 442 & 256 & 630 & 394 & 645 & 955 & 826 & 1,274 & 1,072 & 1,041 & 512 & 419 \\
\hline Leek & & & & & & & & & & & & & 47 & 90 & 142 & 74 & 145 & 124 & 142 & 108 & 204 & 166 & 46 & 121 \\
\hline Limón & & & & & & & & & & & & & 124 & 140 & 140 & 140 & 146 & 162 & 162 & 162 & 164 & 154 & 162 & 162 \\
\hline Maíz & 13,556 & 1,824 & 1,628 & 1,232 & 2,926 & 6,238 & 5,839 & 3,348 & 1,813 & 2,663 & 967 & & 10,350 & 17,351 & 8,710 & 1,720 & 1,872 & 1,754 & 1,601 & 2,002 & 2,091 & 895 & 952 & 685 \\
\hline Mandarina & & & & & & & & & & & & & & 11 & 11 & 11 & 11 & 8 & 7 & 7 & 9 & 11 & 11 & 14 \\
\hline Manzana & & & & & & & & & & & & & 28 & 29 & 20 & 20 & 18 & 4 & 4 & 4 & 2 & 2 & 2 & 2 \\
\hline Melón & 2,084 & 1,264 & 778 & 1,437 & 1,064 & 52 & 1,634 & 1,664 & 1,615 & 1,659 & 2,189 & & 1,663 & 511 & 743 & 260 & 834 & 571 & 394 & 339 & 259 & 212 & 107 & 133 \\
\hline Mostaza & & & & & & & & & & & & & 31 & & 4 & 35 & 12 & 16 & 32 & 33 & 10 & 8 & & 13 \\
\hline Nabo & & & & & & & & & & & & & 10 & 17 & 11 & 11 & 14 & 40 & 25 & & 31 & 8 & 17 & 14 \\
\hline Napa & & & & & & & & & & & & & 11 & 12 & 25 & 24 & 51 & 24 & 33 & 15 & 7 & 14 & 12 & 4 \\
\hline Naranja & & & & & & & & & & & & & 171 & 221 & 221 & 216 & 215 & 209 & 209 & 209 & 218 & 290 & 290 & 285 \\
\hline Nopal & & & & & & & & & & & & & & 26 & 23 & 21 & 21 & 22 & 20 & 20 & 21 & 24 & 26 & 21 \\
\hline Olivo & & & & & & & & & & & & & 14 & & 14 & 14 & 14 & 14 & 14 & 14 & 14 & & & \\
\hline Palma datilera & & & & & & & & & & & & & & 13 & 21 & 21 & 95 & 95 & 90 & 90 & 90 & 109 & 109 & 109 \\
\hline Palma hornato & & & & & & & & & & & & & & & & & & 14 & 14 & 17 & 22 & 20 & 21 & 17 \\
\hline Papa & & & & & & & & & & & & & & 20 & & & 1 & 10 & & & 0 & 0 & & \\
\hline Pastos forrajer & & & & & & & & & & & & & 17 & 8 & & & & & & & & & & \\
\hline Pepino & & & & & & & & & & & & & 84 & 7 & & & 8 & 15 & 21 & 17 & 5 & 34 & 1 & \\
\hline Perejil & & & & & & & & & & & & & 58 & 26 & 69 & 50 & 82 & 160 & 92 & 67 & 157 & 85 & 68 & 110 \\
\hline Plantágo & & & & & & & & & & & & & & & 5 & & & & & & & & & \\
\hline
\end{tabular}




\begin{tabular}{|c|c|c|c|c|c|c|c|c|c|c|c|c|c|c|c|c|c|c|c|c|c|c|c|}
\hline Quelite & & & & & & & & & & & & 130 & 111 & 149 & 25 & 45 & 158 & 46 & 82 & 88 & 80 & 52 & 38 \\
\hline Rábano & 210 & 184 & 138 & 170 & 323 & 338 & 435 & 504 & 523 & 629 & 668 & 643 & 502 & 636 & 624 & 681 & 701 & 859 & 776 & 527 & 592 & 345 & 406 \\
\hline Rapini & & & & & & & & & & & & 103 & 146 & 57 & 93 & 71 & 50 & 100 & 60 & 87 & 28 & 13 & \\
\hline Remolacha & & & & & & & & & & & & & & & 24 & 12 & & & & 0 & 0 & & \\
\hline Ryegrass & 10,673 & 11,388 & 10,717 & 9,717 & 9,705 & 11,339 & 11,641 & 12,825 & 14,380 & 15,244 & 13,923 & 13,528 & 10,566 & 9,616 & 9,812 & 7,357 & 5,623 & 6,649 & 5,488 & 4,882 & 5,487 & 5,234 & 5,175 \\
\hline Sandía & 1,422 & 618 & 630 & 1,037 & 669 & 79 & 845 & 723 & 584 & 909 & 580 & 497 & 233 & 461 & 147 & 484 & 401 & 300 & 239 & 129 & 89 & 194 & 254 \\
\hline Sorgo forrajer & ro 2,352 & 2,553 & 2,345 & 2,164 & 7,224 & 12,267 & 4,355 & 6,519 & 4,468 & 4,114 & 5,172 & 2,561 & 4,123 & 6,389 & 7,480 & 4,661 & 15,495 & 4,537 & 7,142 & 7,243 & 7,753 & 6,965 & 6,345 \\
\hline Sorgo escober & & & & & & & & & & & & 71 & 593 & 2,741 & 986 & 98 & 273 & 85 & 240 & 170 & 95 & & \\
\hline Sorgo grano & 961 & 749 & 403 & 1,186 & 1,012 & 1,809 & 8,301 & 7,245 & 1,327 & 3,675 & 2,981 & 4,017 & 2,792 & 4,177 & 5,225 & 13,413 & 7,744 & 5,121 & 6,797 & 4,145 & 2,061 & 4,336 & 6,502 \\
\hline Tomatillo & & & & & & & & & & & & 59 & 111 & 100 & 93 & 216 & 211 & 102 & 325 & 229 & 471 & 464 & 466 \\
\hline Toronja & & & & & & & & & & & & & 26 & 26 & 17 & 17 & 13 & 14 & 14 & 17 & 17 & 11 & 17 \\
\hline Trigo & 46,474 & 45,330 & 75,415 & 79,311 & 80,797 & 76,929 & 86,253 & 84,442 & 53,098 & 50,572 & 48,374 & 69,390 & 79,683 & 80,018 & 69,658 & 53,159 & 67,224 & 54,913 & 50,636 & 74,273 & 68,033 & 64,926 & 74,394 \\
\hline Varios & & & & & & 3,980 & & & & & 4,796 & 169 & 663 & 125 & 67 & 401 & 331 & 711 & 1,551 & 353 & 457 & 1,247 & 599 \\
\hline Vid & 811 & 1,196 & 1,651 & 1,979 & 2,494 & 2,138 & 1,954 & 1,871 & 1,995 & 1,911 & 1,708 & 1,571 & 735 & 1,348 & 1,179 & 1,109 & 1,139 & 1,085 & 948 & 941 & 911 & 872 & 879 \\
\hline Zacate bermuc & & & & & & & & & & & & & 477 & 770 & 1,773 & 1,881 & 2,175 & 1,993 & 1,993 & 3,613 & 3,626 & & 3,617 \\
\hline Zanahoria & 27 & 17 & 10 & 18 & 55 & 53 & 57 & 28 & 439 & 688 & 476 & 247 & 182 & 424 & 141 & 149 & 238 & 233 & 206 & 158 & 63 & 53 & 56 \\
\hline Total & 198,274 & 174,388 & 169,600 & 169,304 & 210,733 & 201,173 & 209,448 & 199,628 & 173,005 & 161,146 & $165,534161,300$ & 156,200 & 149,424 & 158,118 & 158,444 & 164,521 & 169,902 & 154,630 & 153,324 & 152,933 & 154,855 & 140,355 & 156,883 \\
\hline
\end{tabular}

Fuente: Elaboración a partir de datos de Sagarpa 
Después de 1987, la superficie cosechada bajó a niveles por debajo de las 160 mil hectáreas en promedio. En el gobierno de Carlos Salinas, las políticas de restricción económica significaron una severa disminución de recursos destinados al desarrollo agrícola. En 1988, el presupuesto de la entonces Secretaría de Agricultura y Recursos $\mathrm{Hi}$ dráulicos sufrió una drástica reducción real de 27 puntos porcentuales respecto a 1987, y no volvió a recuperar el nivel de 1987 sino hasta 1993 (cuadro 2). La disminución dela superficiecosechada no havuel to a el evarse a pesar de los recursos extraordinarios de Procampo a partir de 1994. La puesta en vigor del programa Alianza para el Campo en 1996 mejoró ligeramente los precios de los granos y el algodón a través de apoyos públicos, lo que el evó de manera modesta la superficie, pero el efecto sólo al canzó a llegar a 1997; después, el nivel volvió a colocarse por debajo de las 155 mil hectáreas.

El recurso de origen estatal tiene un escaso o nulo impacto en la superficiecosechada debido a los criterios deasignación presupuestal para el desarrollo agropecuario -de la Secretaría de Fomento Agropecuario-. Su limitadísimo monto (cuadro 3) y sus proporciones históricas de escaso gasto de inversión y elevado gasto corriente -25\%-75\% respectivamente en 1989 y 55\%-45\% en 2001 (Coplade, 1990 y Poder Legislativo, 2002)- han hecho que el grado de influencia de la dependencia estatal en el comportamiento del desarrollo agrícola sea modesto.

Frenteal reducido al cance delas instituciones locales, el comportamiento productivo regional responde fundamentalmente a condicionantes provenientes de fuera de la región, las cuales a su vez tienen origen en el marco de políticas y programas nacionales en materia de asignación presupuestal para programas de subsidio a precios a productos e insumos, mismos que se ven afectados por condicionantes internacionales derivados de la apertura económica (Calva, 2000: 87-103). ${ }^{3}$

\footnotetext{
${ }^{3}$ La obra citada del doctor José Luis Calva es una referencia que ilustra con tino el crucial entorno económico del desarrollo agrícola. A bundar sobre este tema, sin embargo, sobrepasa el propósito de este artículo, el cual está limitado al examen de la evolución productiva de la región agrícola del Valle de Mexicali.
} 


\section{Cuadro 2. México: Gasto presupuestario federal} en agricultura y ganadería

\begin{tabular}{|c|c|c|c|c|c|c|}
\hline & \multicolumn{4}{|c|}{ Agricultura y ganadería } & \multirow{2}{*}{$\begin{array}{c}\text { Gasto programable } \\
\text { del gob. federal } \\
\text { (mill. pesos de } \\
\text { 2002) }\end{array}$} & \multirow{2}{*}{$\begin{array}{l}\text { Gasto neto } \\
\text { del sector público } \\
\text { (mill. pesos de } \\
\text { 2002) }\end{array}$} \\
\hline & $\begin{array}{l}\text { Millones pesos } \\
\text { de } 2002\end{array}$ & $\%$ del plB & $\begin{array}{l}\% \text { del gasto } \\
\text { programable }\end{array}$ & $\begin{array}{c}\% \text { del gasto } \\
\text { neto }\end{array}$ & & \\
\hline 1980 & $74,022.9$ & 0.01 & 14.44 & 6.27 & $512,795.7$ & $1,180,217.9$ \\
\hline 1981 & $84,557.9$ & 0.01 & 13.46 & 5.64 & $628,301.7$ & $1,498,476.4$ \\
\hline 1982 & $68,686.9$ & 0.01 & 11.53 & 3.96 & $595,523.7$ & $1,735,726.9$ \\
\hline 1983 & $44,987.7$ & 0.02 & 9.19 & 2.93 & $489,777.7$ & $1,534,179.0$ \\
\hline 1984 & $43,522.7$ & 0.03 & 8.98 & 2.90 & $484,582.8$ & $1,501,270.7$ \\
\hline 1985 & $40,323.3$ & 0.05 & 8.48 & 2.74 & $475,641.8$ & $1,469,538.7$ \\
\hline 1986 & $33,759.9$ & 0.07 & 8.21 & 2.17 & $411,155.5$ & $1,552,901.7$ \\
\hline 1987 & $28,335.8$ & 0.14 & 7.71 & 1.74 & $367,571.2$ & $1,630,702.8$ \\
\hline 1988 & $20,741.5$ & 0.18 & 6.48 & 1.37 & $320,168.3$ & $1,514,947.2$ \\
\hline 1989 & $25,273.9$ & 0.27 & 7.70 & 1.91 & $328,261.7$ & 1,321,887.3 \\
\hline 1990 & $22,800.0$ & 0.30 & 6.68 & 1.84 & $341,457.2$ & $1,240,986.4$ \\
\hline 1991 & $26,415.0$ & 0.44 & 7.18 & 2.43 & $367,705.5$ & $1,087,564.3$ \\
\hline 1992 & $31,635.5$ & 0.62 & 7.84 & 2.93 & $403,626.0$ & $1,080,394.3$ \\
\hline 1993 & $28,023.2$ & 0.57 & 6.13 & 2.57 & $457,196.6$ & 1,091,379.1 \\
\hline 1994 & $47,384.7$ & 0.88 & 8.83 & 4.11 & $536,389.4$ & $1,153,660.2$ \\
\hline 1995 & $38,639.6$ & 0.91 & 8.51 & 3.52 & $454,082.3$ & 1,097,565.6 \\
\hline 1996 & $38,391.8$ & 1.31 & 8.20 & 3.35 & $468,237.2$ & 1,147,536.6 \\
\hline 1997 & $35,285.3$ & 1.37 & 6.27 & 2.81 & $563,063.7$ & $1,254,311.9$ \\
\hline 1998 & $32,057.7$ & 1.38 & 5.60 & 2.68 & $572,513.0$ & $1,194,628.9$ \\
\hline 1999 & $26,287.3$ & 1.18 & 4.40 & 2.06 & $597,830.2$ & 1,276,281.1 \\
\hline 2000 & $27,545.1$ & 1.38 & 4.17 & 1.97 & $659,967.7$ & $1,396,053.5$ \\
\hline 2001 & $34,220.1$ & 1.81 & 5.03 & 2.44 & $679,815.0$ & $1,401,510.6$ \\
\hline 2002 & $35,580.2$ & 1.76 & 4.92 & 2.43 & $723,330.1$ & $1,463,334.3$ \\
\hline
\end{tabular}

Fuente: Elaborado a partir del Banco de Información del Centro de Estudios de las Finanzas Públicas, H. Cámara de Diputados (Deflactor: índice implícito del PIB base $2002=100$ ). Datos de SHCP para porcentaje del PIB. 
Cuadro 3. Baja California: Presupuesto anual de la Secretaría de Fomento Agropecuario

\begin{tabular}{|c|c|c|c|c|c|c|c|c|c|c|c|}
\hline \multirow{2}{*}{ Año } & \multicolumn{2}{|c|}{ SEFOA } & \multicolumn{2}{|c|}{ Total estatal } & \multirow{2}{*}{$\begin{array}{c}\text { SFA/ } \\
\text { Estado } \\
(\%)\end{array}$} & \multirow{2}{*}{ Año } & \multicolumn{2}{|c|}{ SEFOA } & \multicolumn{2}{|c|}{ Total estatal } & \multirow{2}{*}{$\begin{array}{c}\text { SFA/ } \\
\text { Estado } \\
(\%)\end{array}$} \\
\hline & $\begin{array}{c}\text { pesos } \\
\text { corrientes }\end{array}$ & $\begin{array}{c}\text { pesos } \\
\text { constantes }\end{array}$ & $\begin{array}{c}\text { pesos } \\
\text { corrientes }\end{array}$ & $\begin{array}{c}\text { pesos } \\
\text { constantes }\end{array}$ & & & $\begin{array}{c}\text { pesos } \\
\text { corrientes }\end{array}$ & $\begin{array}{c}\text { pesos } \\
\text { constantes }\end{array}$ & $\begin{array}{c}\text { pesos } \\
\text { corrientes }\end{array}$ & $\begin{array}{c}\text { pesos } \\
\text { constantes }\end{array}$ & \\
\hline 1983 & 55,007 & $9,650,351$ & $16,616,253$ & $2,915,132,105$ & 0.33 & 1994 & $17,677,712$ & $61,788,577$ & $1,825,871,000$ & $6,381,932,891$ & 0.97 \\
\hline 1984 & 154,942 & $17,215,778$ & $22,790,000$ & $2,532,222,222$ & 0.68 & 1995 & $14,013,759$ & $32,237,771$ & $2,192,301,000$ & $5,043,250,518$ & 0.64 \\
\hline 1985 & 282,083 & $19,059,662$ & $40,322,722$ & $2,724,508,243$ & 0.70 & 1996 & $46,597,307$ & $83,943,987$ & $2,326,987,000$ & $4,192,014,052$ & 2.00 \\
\hline 1986 & 474,252 & $15,600,395$ & $57,032,876$ & 1,876,081,447 & 0.83 & 1997 & $48,572,600$ & $75,611,146$ & $2,980,955,000$ & $4,640,340,909$ & 1.63 \\
\hline 1987 & $1,083,545$ & $13,733,143$ & $99,535,144$ & $1,261,535,412$ & 1.09 & 1998 & $54,308,330$ & $71,280,129$ & $4,070,955,000$ & $5,343,161,832$ & 1.33 \\
\hline 1988 & $2,257,084$ & $18,871,940$ & $260,512,399$ & 2,178,197,316 & 0.87 & 1999 & $67,102,948$ & $78,409,614$ & $8,710,141,214$ & $10,177,776,600$ & 0.77 \\
\hline 1989 & $3,130,010$ & $21,857,612$ & $442,554,000$ & $3,090,460,894$ & 0.71 & 2000 & $86,566,971$ & $92,833,213$ & $11,761,937,948$ & $12,613,338,282$ & 0.74 \\
\hline 1990 & 8,118,292 & $43,646,731$ & $671,829,000$ & 3,611,983,871 & 1.21 & 2001 & $94,443,530$ & $97,014,412$ & $13,430,470,455$ & $13,796,066,210$ & 0.70 \\
\hline 1991 & $9,583,740$ & $43,365,339$ & $910,331,000$ & 4,119,144,796 & 1.05 & 2002 & $86,621,093$ & $84,179,877$ & $14,582,154,250$ & $14,171,189,747$ & 0.59 \\
\hline 1992 & $10,915,787$ & $44,122,017$ & $1,319,003,000$ & $5,331,459,175$ & 0.83 & 2003 & $90,030,524$ & $85,207,765$ & $16,543,259,000$ & $15,657,068,900$ & 0.54 \\
\hline
\end{tabular}

Fuente: SEFOA y Decretos de Presupuesto de Egresos (Periódico Oficial del Estado de Baja California).

Nota: Pesos constantes con el INPC de la segunda quincena de junio del $2002=100$. 


\section{Rendimientos físicos y volumen de producción}

Los rendimientos físicos son un indicador particularmente importante porque reflejan el avance tecnológico, es decir, el conocimiento científico que respalda el desarrollo agrícola y productivo. Si este conocimiento serezaga, la productividad dela tierra y delos insumos aplicados se ve disminuida y, en consecuencia, se observa un retroceso o estancamiento del desarrollo.4

En estepunto es importanteseñalar quetanto el rendimiento físico como los demás indicadores de desarrollo productivo se ven afectados por la disponibilidad oportuna y suficiente de recursos de los que disponen los productores, tan diferentes como sean sus condiciones económicas individual es y la disponibilidad y acceso a recursos públicos.

También es necesario hacer notar que la línea tendencial de este indicador en los diferentes cultivos no refleja la aplicación derecursos públicos como Procampo y A lianza para el Campo; sí refleja, en cambio, afectaciones por plagas, como la mosquita blanca que deterioró severamentela producción dealgodón en 1992. La productividad física no seal tera por Procampo y otros programas deA lianza debido a que en su diseño político la asignación de los recursos tienela característica de no destinarse a las vertientes que afectan directamente el modo de producción, como son los cambios en la aplicación detecnología, o indirectamente como la asignación de apoyos por unidad producida, lo cual sería un al iento significativo a producir más cambiando el modo deproducción.

Utilizando las series de tiempo de la productividad física por hectárea de los siete principales cultivos de la región, se pueden concluir los comportamientos negativos del rye-grass y el sorgo forrajero, el estancamiento del al godón y el espárrago, y un modesto incremento del cebollín, el trigo y la alfalfa (figuras 2 y 3 ).

${ }^{4}$ Sobre la relación entre conocimiento y desarrollo de tecnología agrícola y el comportamiento productivo, puede consultarse una excelente experiencia mexicana: "El Plan Puebla”, en C.H. Díaz, S.L. Jiménez, R.J. Laird y F.A. Turrent (1999). 
Cuadro 4. Valle de Mexicali: Rendimientos físicos de principales cultivos (toneladas/ hectárea)

Trigo Algodón Alfalfa Cebollín Espárrago Sorgo Ryegrass forrajero

\begin{tabular}{llllllll}
\hline 1980 & 4.4 & 3.7 & 10.6 & 11.8 & 2.8 & 48.0 & 60.0 \\
1981 & 4.5 & 3.1 & 11.1 & 11.7 & 3.1 & 48.0 & 56.0 \\
1982 & 5.3 & 3.2 & 11.3 & 11.9 & 3.4 & 48.0 & 56.0 \\
1983 & 5.5 & 3.5 & 10.0 & 11.1 & 3.4 & 42.6 & 60.0 \\
1984 & 4.7 & 3.1 & 12.5 & 16.9 & 3.4 & 27.7 & 60.0 \\
1985 & 4.5 & 4.0 & 12.2 & 11.3 & 3.4 & 20.5 & 35.0 \\
1986 & 4.7 & 3.2 & 12.6 & 10.3 & 2.9 & 19.6 & 35.0 \\
1987 & 4.7 & 4.1 & 13.7 & 11.1 & 3.1 & 20.6 & 48.0 \\
1988 & 4.6 & 3.9 & 10.4 & 11.6 & 5.1 & 15.6 & 55.2 \\
1989 & 4.4 & 3.5 & 8.6 & 9.2 & 3.1 & 14.3 & 34.1 \\
1990 & 5.3 & 3.3 & & 8.6 & 3.6 & 19.6 & 36.0 \\
1991 & & & & & & & \\
1992 & 4.9 & 1.7 & 11.5 & 12.3 & 3.3 & 15.4 & 34.0 \\
1993 & 5.7 & 3.1 & & & & & 39.6 \\
1994 & 6.2 & 3.8 & 13.2 & 11.9 & 3.2 & 38.7 & 43.0 \\
1995 & 5.4 & 3.3 & 14.0 & 11.8 & 3.6 & 44.1 & 39.6 \\
1996 & 5.2 & 3.4 & 15.3 & 12.5 & 3.4 & 40.0 & 39.0 \\
1997 & 6.1 & 4.3 & 16.7 & 12.3 & 4.0 & 11.2 & 38.5 \\
1998 & 7.2 & 3.2 & 15.9 & 12.4 & 3.8 & 8.7 & 40.7 \\
1999 & 6.7 & 3.4 & 15.4 & 12.6 & 3.1 & 11.3 & 45.0 \\
2000 & 5.8 & 3.6 & 14.9 & 12.3 & 4.3 & 13.0 & 40.2 \\
2001 & 5.6 & 3.6 & 14.3 & 12.1 & 4.3 & 13.3 & 41.2 \\
2002 & 5.9 & 3.4 & 14.1 & 13.2 & 3.4 & 12.1 & 48.0 \\
\hline
\end{tabular}

Fuente: Elaboración a partir de datos de Sagarpa.

Una conclusión que surge al observar el comportamiento de la productividad física de los cultivos es que en general no han tenido cambios positivos sustanciales; por el contrario, son más evidentes el estancamiento y los comportamientos negativos.

Consistente con el comportamiento de la superficie cosechada y de los rendimientos físicos, el análisis de la tendencia del volumen de producción de los cultivos más importantes muestra como un caso grave el del algodón, cuyo desplome de los años ochenta a los noventa representa más del 50\%. La plaga de 1992 hizo desaparecer literalmente el cultivo de la región y, a pesar de su recuperación, ésta no ha 
Figura 2.

Tendencia de los rendimientos físicos de los principales cultivos en el Valle de Mexicali (toneladas / hectárea)

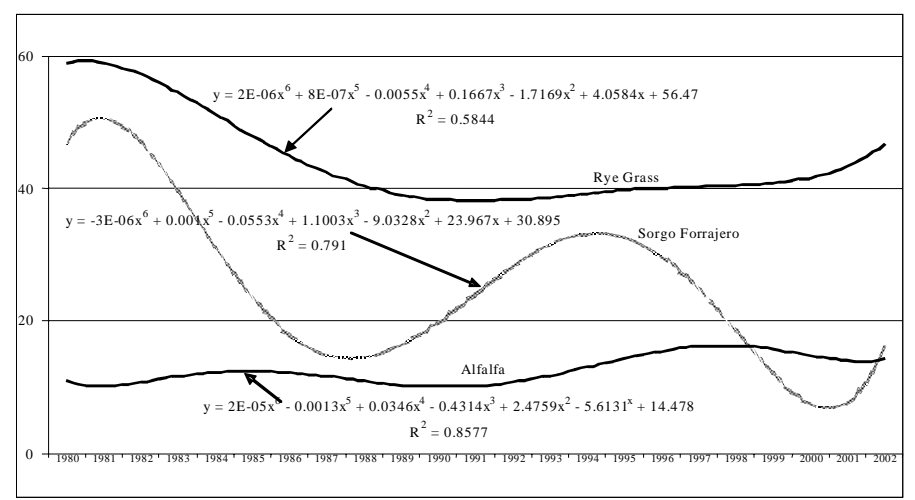

Fuente: Cuadro 4.

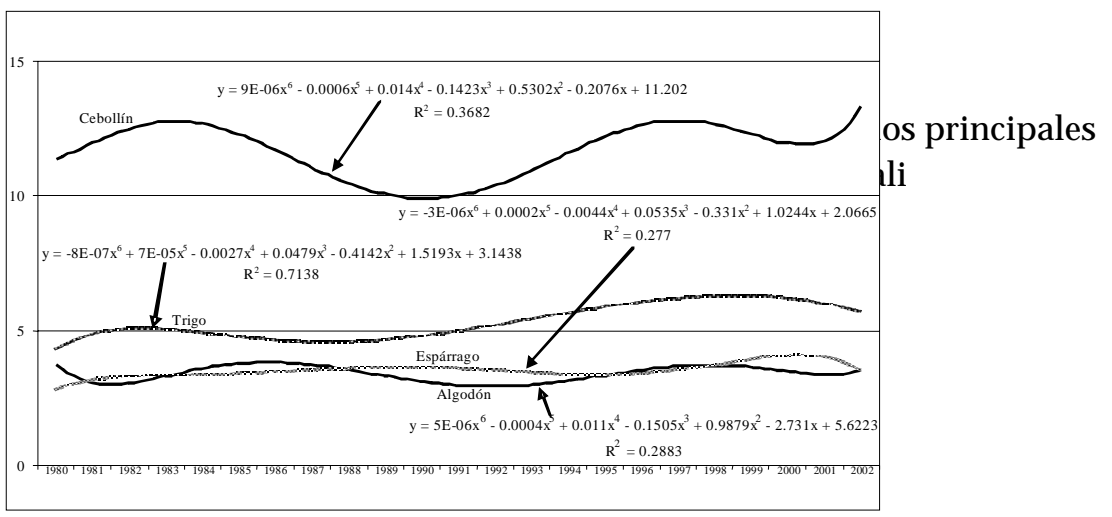

Fuente: Cuadro 4. 
vuel to a tener los volúmenes de producción de principios de los años ochenta (cuadro 5). Comportamiento similar de tendencia negativa muestra el rye-grass, con una pendiente mayor debida a la drástica disminución deprogramas de producción de carne en la región (SEFOA, 91: 35-38) y en consecuencia la demanda de este forraje. La disminución en los rendimientos se sumó para que hacia finales de los noventa el volumen de producción cayera prácticamente a una quinta parte comparado con los principios de los ochenta (figuras 4 y 5).

El trigo, dada su naturaleza alternativa al cultivo del al godón, muestra un crecimiento en la producción, pero éste no se debe a una eleva-

Cuadro 5. Valle de Mexicali: Volumen de producción de los diez principales cultivos

(toneladas)

\begin{tabular}{rrrrrrrr}
\hline & Trigo & $\begin{array}{c}\text { Algodón } \\
\text { hueso }\end{array}$ & $\begin{array}{c}\text { Alfalfa } \\
\text { henificada }\end{array}$ & Cebollín & Espárrago & $\begin{array}{r}\text { Sorgo } \\
\text { forrajero }\end{array}$ & Rye grass \\
\hline 1980 & 204,145 & 241,605 & 138,452 & 19,597 & 5,324 & 112,896 & 640,380 \\
1981 & 203,779 & 218,612 & 153,089 & 16,046 & 5,040 & 122,544 & 637,728 \\
1982 & 399,852 & 118,179 & 153,764 & 11,126 & 5,046 & 112,560 & 600,152 \\
1983 & 433,673 & 123,731 & 139,540 & 18,609 & 5,209 & 92,160 & 583,020 \\
1984 & 376,837 & 199,744 & 177,459 & 21,628 & 6,249 & 200,039 & 582,300 \\
1985 & 345,185 & 153,425 & 199,665 & 23,855 & 7,735 & 251,395 & 396,865 \\
1986 & 405,389 & 111,125 & 220,576 & 20,430 & 6,045 & 85,271 & 407,435 \\
1987 & 396,442 & 148,732 & 170,219 & 24,534 & 8,929 & 134,166 & 616,241 \\
1988 & 243,096 & 214,670 & 148,101 & 36,109 & 13,887 & 69,792 & 793,632 \\
1989 & 220,304 & 130,986 & 152,978 & 44,533 & 8,881 & 58,891 & 519,210 \\
1990 & 254,569 & 134,043 & & 23,822 & 11,156 & 101,522 & 501,228 \\
1991 & & 124,975 & & & & 36,219 & 626,782 \\
1992 & 338,229 & 29,452 & 212,830 & 43,637 & 9,862 & 39,469 & 459,952 \\
1993 & 455,746 & 2,044 & & 43,760 & 7,865 & & 418,413 \\
1994 & 497,638 & 36,619 & 228,581 & 46,521 & 6,518 & 247,104 & 413,488 \\
1995 & 376,423 & 89,197 & 289,630 & 39,326 & 6,007 & 329,941 & 388,359 \\
1996 & 277,850 & 146,338 & 286,441 & 48,255 & 5,923 & 186,445 & 286,923 \\
1997 & 411,329 & 146,080 & 298,178 & 60,725 & 7,606 & 173,788 & 216,503 \\
1998 & 392,650 & 139,308 & 315,334 & 58,913 & 7,046 & 39,416 & 270,622 \\
1999 & 339,313 & 118,640 & 320,596 & 65,088 & 5,807 & 80,952 & 246,960 \\
2000 & 428,819 & 54,075 & 357,339 & 46,520 & 8,011 & 94,189 & 196,207 \\
2001 & 381,432 & 85,081 & 372,175 & 54,322 & 8,528 & 103,425 & 226,064 \\
2002 & 386,299 & 43,600 & 380,700 & 56,351 & 9,274 & 84,115 & 251,232 \\
& & & & & & & \\
\hline
\end{tabular}

Fuente: Elaboración con datos de Sagarpa. 
José ZaVALA ÁlvareZ/ EstancAmIENTO y deSALIENTO DEL DESARROLLO PRODUCTIVO

Figura 4.

Tendencia del volumen de producción de los principales cultivos en el Valle de Mexicali

(toneladas)

Fuente: Cuadro 5.

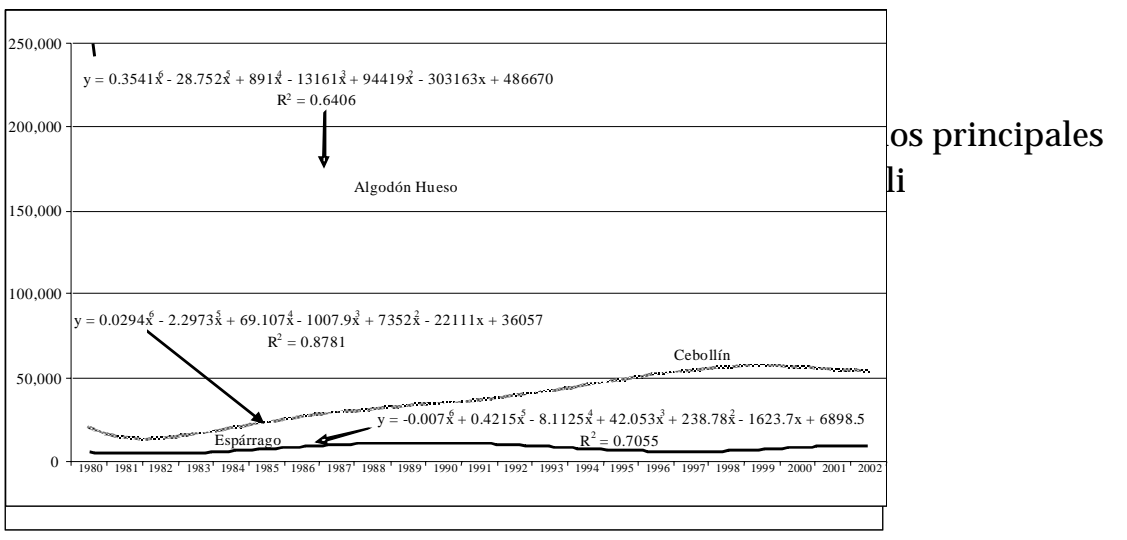

Fuente: Cuadro 5. 
ción en rendimientos, sino al incremento de la superficie cosechada. El carácter alternativo del trigo deriva de la decisión del productor que históricamente ha optado por alternar los cultivos de algodón y trigo cuando al guno de ellos muestra menor rentabilidad en al gún año agrícola, o cuando siembra uno de ellos por varios ciclos y decide cambiar de cultivo. El conocimiento que los productores tienen sobre estos cultivos es otro factor importante que incideen su decisión para elegir uno u otro.

La producción de leche en la parte costera del estado ha alimentado -debido al incremento en la demanda- una tendencia crecienteen la producción de alfalfa como consecuencia del incremento de la superficie cosechada, sin que ello haya arrojado una mejora significativa delosrendimientos. Duranteel periodo en estudio, el sorgo forrajero (sudán) no muestra tendencia negativa a pesar de que sus rendimientosfísicos sí caen, debido a queel volumen de producción es compensado por el incremento de la superficie cosechada. El establecimiento de explotaciones privadas de producción de carnebovina, queempezaron a localizarsey a crecer a partir de la mitad de los años noventa, explica en parte que la producción de forrajes como éstese mantuviera eincluso se incrementara en algunos años.

El volumen de producción de hortalizas como el cebollín y el espárrago está determinado por el mercado externo, ya que las exportaciones e importaciones marcan la pauta para el comportamiento de la producción. El cebollín es la hortaliza más importante y dinámica: la superficie cosechada ha mostrado un modesto crecimiento, pero su comportamiento ha el evado el volumen producido. El espárrago, por su parte, se mantiene en el mismo nivel de producción.

De los principales cultivos, en resumen, se produce menos algodón y ryegrass, más trigo, alfalfa y cebollín, y lo mismo de sorgo forrajero y espárrago.

\section{Rendimientos económicos y valor de producción}

Al comportamiento modesto o poco deseable de la productividad física de la región se suma el hecho de que la tendencia dela produc- 
tividad económica por unidad de superficie 5 -síntesis además de condicionantes adicionales como los precios de insumos y de los propios cultivos- padece un consistente estancamiento e incluso una ligera declinación (figuras 6 y 7).

El rendimiento económico -no utilidad- en general de la producción agrícola del Valle de Mexicali pasó de un nivel de poco más de 22 mil quinientos pesos por hectárea en 1980 a 14 mil 181 pesos en 2001 (cuadro 6). Por razones evidentes, el rendimiento económico sí se ve modificado por la aplicación de apoyos o subsidios, tanto directos como indirectos; en ese sentido, en la línea tendencial de este indicador se observan variaciones a la alza en años especiales como 1994 de Procampo y 1996 de Alianza para el Campo. Sin embargo, como ya se ha mencionado, el efecto es sumamente breve puesal cabo deuno y dos

Figura 6.

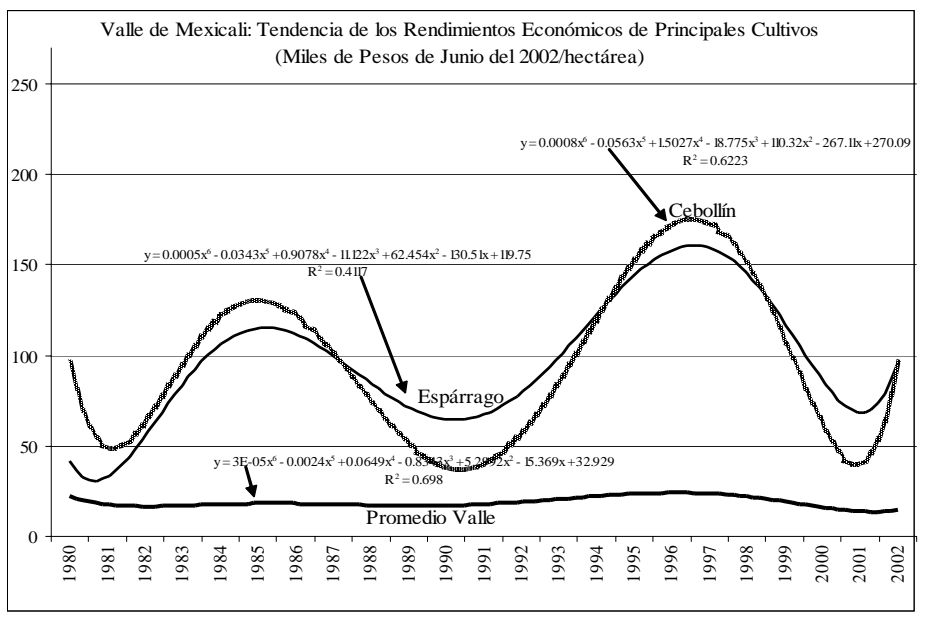

Fuente: Cuadro 6.

${ }^{5}$ El rendimiento económico al que se hace referencia es el valor monetario (en pesos) obtenido por unidad de superficie (hectárea). 
Figura 7.

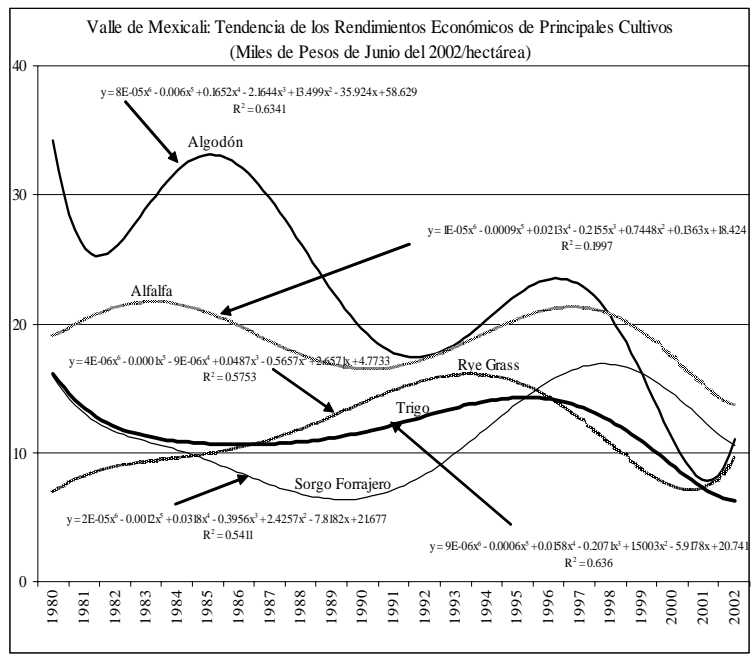

Fuente: Cuadro 6.

años, el comportamiento tendencial retoma su menor nivel y en general -aunque con pendiente ligera- se dirige al deterioro. No se aprecia ningún efecto en este indicador, al igual queen los demás, de la aplicación de recursos presupuestales de origen estatal. Revisando la tendencia y nivel de cultivos importantes se encuentra que, aunque con marcadas fluctuaciones, sólo el espárrago y el cebollín se encuentran por encima del promedio del Valle. El algodón se mantenía también arriba del promedio, pero a partir de 1996 su nivel secolocó por debajo. La alfalfa es uno de los forrajes que con algunas dificultades y a través de una diferencia reducida se ha comportado con rendimientos económicos superiores al promedio dela región. El trigo, el rye-grass y el sorgo forrajero son cultivos que tradicionalmente ocupan menores niveles de productividad económica por hectárea que el nivel promedio regional. Como consecuencia del comportamiento histórico de la superficie cosechada y el estancamiento de los rendimientos de cultivos importantes, el valor dela producción agrícola del ValledeM exicali 
Cuadro 6. Valle de M exicali: Rendimientos económicos de principales cultivos (miles de pesos de junio del 2002/ Hectárea)

\begin{tabular}{|c|c|c|c|c|c|c|c|c|}
\hline & Trigo & Algodón & Alfalfa & Cebollín & Espárrago & $\begin{array}{c}\text { Sorgo } \\
\text { forrajero }\end{array}$ & Rye-grass & $\begin{array}{l}\text { Promedio } \\
\text { general Valle }\end{array}$ \\
\hline 1980 & 16.468 & 35.822 & 17.201 & 93.453 & 41.280 & 13.692 & 7.824 & 22.597 \\
\hline 1981 & 13.096 & 18.825 & 25.197 & 61.916 & 35.008 & 18.847 & 5.675 & 16.288 \\
\hline 1982 & 10.617 & 31.477 & 16.176 & 44.108 & 64.972 & 9.937 & 10.701 & 16.257 \\
\hline 1983 & 12.447 & 37.930 & 24.667 & 105.681 & 59.901 & 5.252 & 8.457 & 19.491 \\
\hline 1984 & 12.907 & 24.767 & 24.947 & 127.292 & 76.182 & 14.100 & 13.284 & 19.175 \\
\hline 1985 & 11.223 & 26.039 & 18.155 & 90.089 & 212.938 & 10.579 & 5.915 & 17.293 \\
\hline 1986 & 8.956 & 28.827 & 13.165 & 182.709 & 72.398 & 6.765 & 10.925 & 15.497 \\
\hline 1987 & 7.142 & 39.908 & 17.362 & 94.398 & 47.379 & 5.848 & 8.833 & 15.723 \\
\hline 1988 & 11.864 & 23.242 & 22.277 & 40.910 & 127.668 & 7.631 & 18.701 & 19.555 \\
\hline 1989 & 12.017 & 26.317 & 18.806 & 49.949 & 64.544 & 8.148 & 8.325 & 18.572 \\
\hline 1990 & 14.579 & 23.430 & 21.985 & 62.114 & 81.266 & 10.532 & 13.655 & 18.513 \\
\hline \multicolumn{9}{|l|}{1991} \\
\hline 1992 & 11.802 & 6.153 & 13.302 & 46.838 & 55.974 & 0.429 & 15.117 & \\
\hline \multicolumn{9}{|l|}{1993} \\
\hline 1994 & 13.327 & 20.296 & 15.702 & 112.693 & 66.040 & 15.549 & 17.287 & 19.277 \\
\hline 1995 & 10.765 & 28.858 & 13.802 & 133.772 & 205.876 & 12.176 & 16.389 & 21.162 \\
\hline 1996 & 17.855 & 23.013 & 23.432 & 189.418 & 232.941 & 18.014 & 14.388 & 26.335 \\
\hline 1997 & 13.385 & 25.521 & 32.536 & 252.363 & 104.122 & 17.232 & 11.370 & 28.431 \\
\hline 1998 & 12.890 & 18.235 & 18.821 & 84.711 & 129.242 & 14.616 & 10.309 & 20.715 \\
\hline 1999 & 10.834 & 11.150 & 17.978 & 75.060 & 80.954 & 17.433 & 8.886 & 17.689 \\
\hline 2000 & 8.805 & 15.286 & 15.475 & 72.552 & 108.392 & 13.534 & 7.284 & 16.109 \\
\hline 2001 & 6.611 & 7.521 & 14.129 & 75.182 & 100.024 & 12.788 & 8.464 & 14.181 \\
\hline 2002 & 6.620 & 10.881 & 15.090 & 79.974 & 78.552 & 10.680 & 8.863 & 14.767 \\
\hline
\end{tabular}

Fuente: Elaboración a partir de datos de Sagarpa. 
refleja, en las últimas dos décadas, una tendencia general de declive (figura 8).

El valor de la producción condensa el volumen de producción con los precios-o ingresos- agrícolas que seven complementados por subsidios, así se pueden explicar las variaciones a la alza o a la baja en algunos añoso periodos en particular. Las variaciones duranteel periodo responden a las mismas razones que se señalan en el apartado anterior sobre superficie cosechada: a mitad de los ochenta, los excedentes deagua en la región y los recursos públicos deorigen federal quealentaron el cultivo deforrajes, después las restricciones económicas dela política del gobierno federal, seguidas por la puesta en vigor de PROCAMPO y Alianza para el Campo, cuyo efecto tuvo muy poco alcance temporal.

\section{Diversificación o especialización productiva}

Los datos disponibles proporcionan una información interesante respecto a la diversificación productiva de la región. A partir delas cédulas decultivos y utilizando los datos de superficiecosechada y valor de la producción por cada uno delos cultivosen los años disponibles (cuadros 1 y 7), se calculó el índice de concentración de Gini (cuadro 8) y la función tendencial deéstea lo largo delasúltimas dos décadas (figura9).

Contra lo que pudiera esperarse-mayor diversificación productiva-, tendencialmente la producción de la región se concentra cada vez más en pocos cultivos, no sólo en cuanto a la superficie que se cultiva de cada uno de éstos, sino también en cuanto al valor económico queaportan. En otras palabras, a la cosecha demayores superficies de pocos cultivos se agrega también mayor aportación de menos cultivos al val or total dela producción agrícola. Es importante considerar esto último porqueel valor dela producción no sólo sedetermina en función del volumen producido -derivado a la cantidad de superficie cosechada-, sino que también se ve impactado por los precios y las subvenciones existentes.

Según este índice, en los años ochenta -primera mitad del periodo observado- el patrón de cultivos fue comparativamente más diversificado que en los noventa -segunda mitad-, es decir, la superficie cosechada se distribuyó más equitativamente entre los diferentes 
Figura 8.

Tendencia real del valor dela producción agrícola en el Valle de Mexicali

(miles de pesos de junio de 2002)

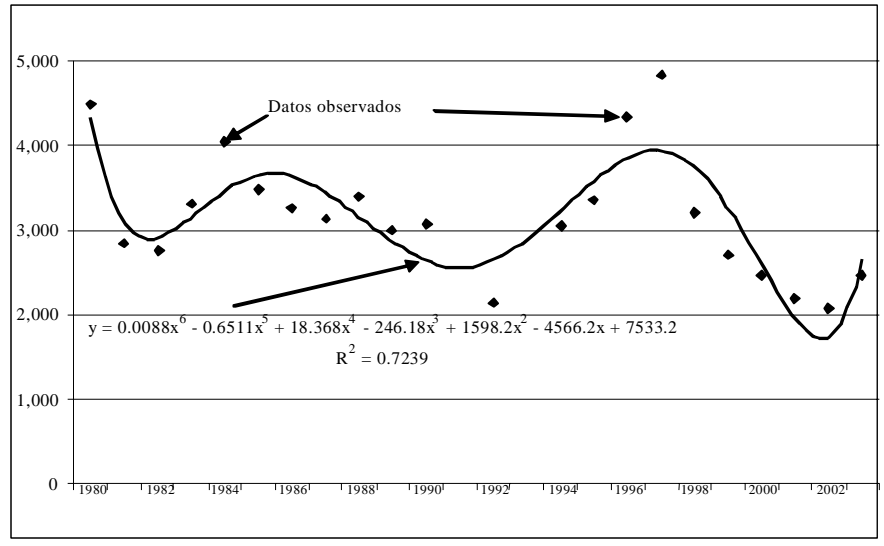

Fuente: Cuadro 7.

cultivos; la misma relación comparativa se aprecia a través del valor de la producción.

El índicedeGini no supera el nivel de 0.8 durantelos ochenta, pero a partir de 1992 y hasta la fecha tiene un comportamiento superior. La predominancia de cultivos como el trigo y el al godón, seguidos de la alfalfa, el sorgo forrajero y hortalizas como el cebollín, hacen que el patrón decultivos dela región éstealtamenteconcentrado, es decir, la diversificación productiva del Valle de Mexicali, en términos objetivos, es cada vez más reducida.

En el fomento dela diversificación productiva, el papel del gobierno local ha sido sumamente modesto a pesar de que en los planes de gobierno estatales el aliento a la diversificación ha tenido, al menos en el discurso oficial, un lugar especial; incluso se han destinado recursos presupuestales y apoyado convenios de comercialización para cultivos como el girasol, la canola, la higuera y otros (COPLADE, 1990, 1996). LOS resultados de estos esfuerzos han sido francamente irrelevantes, la región tiende más a una mayor especialización agrícola. 


\section{Cuadro 7.}

Valle de Mexicali: Valor de la producción por cultivo (millones de pesos corrientes)

\begin{tabular}{|c|c|c|c|c|c|c|c|c|c|c|c|c|c|c|c|c|c|c|c|c|c|c|c|c|}
\hline & 1980 & 1981 & 1982 & 1983 & 1984 & 1985 & 1986 & 1987 & 1988 & 1989 & 1990 & 1991 & 1992 & 1993 & 1994 & 1995 & 1996 & 1997 & 1998 & 1999 & 2000 & 2001 & 2002 & 2003 \\
\hline Acelga & & & & & & & & & & & & & & & & 0.37820 & 0.26000 & 0.50107 & & 0.07200 & 0.21910 & 0.61940 & & \\
\hline Ajo & 0.04694 & 0.02214 & 0.06639 & 0.04240 & 0.09317 & 0.12986 & 0.12859 & 0.15628 & 0.59360 & 0.52550 & 0.46800 & & 4.99951 & 5.57851 & 9.69263 & 14.71990 & 11.15310 & 7.51977 & 15.17880 & 33.47802 & 19.79385 & 25.43750 & 22.41000 & 26.56621 \\
\hline Ajonjoli & 0.20413 & 0.05061 & 0.05012 & 0.07430 & 1.07905 & 2.69772 & 5.47770 & 8.77641 & 3.47000 & 3.85093 & 13.08291 & & & & & & & & & & & & & \\
\hline Alcachofa & & & & & & & & & & & & & 0.09450 & & & & & & & & & & & \\
\hline Alfalfa & 0.27690 & 0.55112 & 0.69194 & 1.95356 & 3.19425 & 4.39263 & 7.01432 & 17.02190 & 37.84800 & 47.80575 & 61.74389 & & 60.65655 & & 77.71754 & 124.54090 & 243.46940 & 372.70500 & 283.80060 & 320.59240 & 346.61883 & 357.28800 & 418.77000 & 467.44020 \\
\hline Algodon & 2.89926 & 2.08114 & 3.62786 & 7.61529 & 14.50995 & 14.72884 & 30.25440 & 115.05765 & 153.27331 & 140.22457 & 175.86720 & & 27.11763 & & 56.10031 & 336.27269 & 552.86496 & 554.49923 & 607.38157 & 335.08738 & 214.88553 & 173.70566 & 142.35374 & 358.24669 \\
\hline Apio & & & & & & & & & & & & & 1.21389 & 0.78926 & 1.53600 & 1.65000 & 0.74250 & 0.28858 & 22.31390 & 12.43062 & 2.00880 & 3.12912 & 2.13486 & 3.34750 \\
\hline Avenaforr. verde & & & & & & & & & & & & & 5.13162 & 1.97586 & 2.03320 & 7.34831 & 5.25789 & 6.31960 & 18.42324 & 11.50380 & 8.65746 & 17.83575 & 14.80715 & 17.78386 \\
\hline Berenjena & & & & & & & & & & & & & 0.08501 & & & & & & & & & & & \\
\hline Betabel & & & & & & & & & & & & & 0.20003 & 0.40963 & 1.07255 & 1.49796 & 0.88240 & 0.62101 & 3.35916 & 5.94000 & 5.48100 & 5.86920 & 1.16816 & 3.89747 \\
\hline Boichoi & & & & & & & & & & & & & 0.13188 & 0.37353 & 0.43200 & 0.15840 & 1.64160 & 0.16709 & 0.04970 & 0.02220 & 0.37310 & 0.18490 & 0.13110 & \\
\hline Brocoli & 0.00033 & 0.00739 & & 0.00589 & 0.05997 & 0.21293 & 0.17674 & 0.09731 & 0.97382 & 2.75408 & 1.09314 & & 3.87429 & 2.03454 & 10.71360 & 1.55000 & 8.93080 & 12.06558 & 17.50470 & 24.99348 & 19.01088 & 22.46627 & 5.96160 & 12.08358 \\
\hline Cacahuate & & & & & & & & & & & & & & & & & & & & 0.10200 & & & & 0.01619 \\
\hline Calabacita & & & & & & & & & & & & & 0.35797 & 0.09900 & 1.96150 & 2.54550 & 6.10230 & 6.91518 & 3.05599 & 8.80106 & 9.50214 & 11.18970 & 7.25525 & 12.17884 \\
\hline Calabaza & & & & & & & & & & & & & 0.11328 & 0.01081 & & & & & & & & & & \\
\hline Canola & & & & & & & & & & & & & & & & & & & & 0.56160 & 0.00552 & & & \\
\hline Cártamo & 0.05062 & 0.02815 & 0.04877 & 0.10412 & 0.18415 & 0.14058 & 0.52119 & 1.88132 & 3.47749 & 6.37277 & 7.21722 & & 2.66493 & 7.19875 & 6.12989 & 7.55055 & 24.63920 & 9.04590 & 3.52395 & 24.06939 & 8.98448 & 2.50305 & 5.19660 & 12.46345 \\
\hline Cebada & 0.25629 & 0.27422 & 0.47739 & 0.58362 & 0.76069 & 0.66748 & 1.95098 & 4.30896 & 8.79200 & 9.70792 & 12.71001 & & 1.91115 & 0.69300 & 0.52225 & 1.70450 & 1.53395 & 1.75030 & 1.61150 & 0.71760 & 0.74593 & 5.10224 & 11.52000 & 15.80500 \\
\hline Cebolla & 0.00912 & 0.01854 & 0.02890 & 0.02049 & 0.05134 & 0.06147 & 0.18171 & 0.24665 & 1.64818 & 4.08661 & 1.41415 & & 3.61106 & 7.88058 & 8.08491 & 10.55500 & 10.14390 & 9.26638 & 20.44320 & 46.77557 & 33.30556 & 26.06311 & 12.51558 & 7.67446 \\
\hline Cebollín & 0.19115 & 0.13413 & 0.12963 & 1.00114 & 1.47074 & 2.80930 & 11.03286 & 16.38889 & 15.24488 & 34.65226 & 32.10330 & & 41.05548 & 41.59431 & 126.49325 & 194.05280 & 404.63082 & 798.59203 & 305.75270 & 332.62027 & 254.98415 & 329.22250 & 351.65447 & 298.21706 \\
\hline Chard & & & & & & & & & & & & & & 0.04147 & 0.05184 & & & & & & & & & \\
\hline Chícharo & & & & & & & & & & & & & 0.71400 & & & & & & & 0.30267 & 2.19645 & & & 0.26130 \\
\hline Chileverde & & & & & & & & & & & & & 0.30188 & 0.02112 & 0.24114 & 0.63510 & 0.70280 & 2.111100 & 4.05720 & 4.31930 & 7.78995 & 3.76987 & 2.67620 & 1.96906 \\
\hline Cilantro & & & & & & & & & & & & & 1.01491 & 1.30094 & 3.19550 & 1.97050 & 3.70583 & 26.72500 & 5.76540 & 12.52180 & 14.64884 & 17.00565 & 14.85855 & 13.47079 \\
\hline Col & & & & & & & & & & & & & 0.60770 & 2.31908 & 3.48075 & 2.15760 & 2.02725 & 2.16315 & 3.81325 & 6.71370 & 8.81121 & 3.02746 & 1.08800 & 1.69400 \\
\hline Coliflor & & & & & & & & & & & & & 0.11008 & & 1.84680 & 1.21000 & 1.93590 & 2.44069 & 0.40000 & 2.16258 & 5.80371 & 1.44963 & 6.46931 & 2.12597 \\
\hline Cominos & & & & & & & & & & & & & & & & & 0.00350 & & & & & & & \\
\hline Daikon & & & & & & & & & & & & & 0.20642 & 0.21450 & 0.15580 & & & & & 3.45950 & & & & \\
\hline Ejote & & & & & & & & & & & & & 0.02688 & & 0.02346 & & & 0.01783 & 0.14550 & 0.23617 & 0.27537 & 0.02240 & & 0.34856 \\
\hline Espárrago & 0.09583 & 0.09071 & 0.30274 & 0.52088 & 1.24978 & 7.16625 & 4.54584 & 10.71480 & 41.43550 & 26.82062 & 46.85520 & & 41.76557 & & 38.06512 & 150.17500 & 227.20628 & 128.02419 & 181.58951 & 127.75400 & 202.65300 & 193.58560 & 220.35024 & 210.21236 \\
\hline Espinaca & 0.00333 & 0.00166 & 0.00301 & 0.01814 & 0.00480 & 0.02188 & 0.18500 & 0.42352 & 0.60452 & 0.87750 & 1.22529 & & 0.68688 & 0.26093 & 0.66092 & 0.69598 & 0.47520 & 3.62344 & 1.38964 & 1.85086 & 2.13072 & 4.93900 & 4.33188 & 5.06460 \\
\hline Eucalipto & & & & & & & & & & & & & & & & 0.01968 & 0.03685 & 0.04047 & 0.04880 & 0.05040 & 0.06062 & 0.09856 & 0.14445 & 0.14777 \\
\hline Girasol & & & & & & & & & & & & & 0.25288 & & & & & & & 0.09850 & & & & \\
\hline
\end{tabular}




\begin{tabular}{|c|c|c|c|c|c|c|c|c|c|c|c|c|c|c|c|c|c|c|c|c|c|c|c|}
\hline \multicolumn{24}{|l|}{ Haba } \\
\hline Higuera & & & & & & & & & & & & 0.01344 & & & & & 0.32850 & 0.24000 & 0.19440 & 0.41650 & & & \\
\hline \multicolumn{24}{|l|}{ Hortalizas } \\
\hline Flor & & & & & & & & & & & & 0.07338 & 0.03944 & & 0.25500 & 0.01380 & & & & & & & \\
\hline Fresa & & & & & & & & & & & & & & & & & & & & & & & 1.15596 \\
\hline Frijol & & & & & & & & & & & & 0.66594 & & & & & & & & & & 0.02291 & 0.24729 \\
\hline Gay-lan & & & & & & & & & & & & 0.11245 & & & & 0.53820 & & & & & & & \\
\hline jitomate & & & & & & & & & & & & 1.03735 & & 1.07783 & 0.65100 & 4.00020 & 4.99680 & 8.03480 & 1.21023 & 1.95475 & 3.37615 & 1.10397 & 3.16444 \\
\hline Kenaf & & & & & & & & & & & & 0.01400 & & & & & & & & & & & \\
\hline Kai-laan & & & & & & & & & & & & & & & & & & 0.27000 & 1.33650 & 0.17133 & 1.48944 & & \\
\hline Kale & & & & & & & & & & & & 0.20618 & 0.43818 & 0.21360 & 0.22050 & 0.11340 & 0.15699 & 1.33000 & 0.90000 & 1.95160 & 2.15124 & 1.55820 & 0.62622 \\
\hline Kohlrabi & & & & & & & & & & & & & 0.06584 & 0.14000 & 0.70000 & 0.64038 & 1.66600 & & 1.80320 & 0.55664 & 1.47250 & 1.39249 & \\
\hline Lechuga & 0.17734 & 0.01432 & 0.01564 & 0.05535 & 0.27893 & 0.49401 & 0.44037 & 0.50536 & 4.82700 & 8.63680 & 8.15360 & 2.03189 & 2.18400 & 8.56800 & 20.74140 & 28.25940 & 98.96110 & 49.75530 & 132.99750 & 130.67028 & 118.29066 & 60.96948 & 61.42900 \\
\hline Leek & & & & & & & & & & & & 0.46988 & 0.74839 & 2.31432 & 1.33672 & 25.26263 & 24.96820 & 15.33180 & 10.40650 & 21.74025 & 13.96615 & 4.23950 & 11.13359 \\
\hline Limón & & & & & & & & & & & & 1.80730 & & 1.62052 & 2.52000 & 2.75940 & 3.37218 & 4.09875 & 4.42000 & 4.85940 & 4.88373 & 4.85680 & 4.63145 \\
\hline Maíz & 0.10466 & 0.01181 & 0.03602 & 0.06853 & 0.21484 & 1.16370 & 1.82179 & 3.39111 & 3.68964 & 10.23609 & 8.72460 & 26.41909 & & 17.10585 & 6.83590 & 9.94110 & 11.12627 & 7.66125 & 11.28018 & 11.78300 & 5.18757 & 5.49630 & 4.02431 \\
\hline Mandarina & & & & & & & & & & & & & & 0.13464 & 0.14300 & 0.16837 & 0.13200 & 0.15080 & 0.16166 & 0.27300 & 0.18560 & 0.19058 & 0.29840 \\
\hline Manzana & & & & & & & & & & & & 0.07360 & & 0.07500 & 0.15300 & 0.11700 & 0.02650 & 0.04400 & 0.03936 & 0.02000 & 0.01709 & 0.01435 & 0.01764 \\
\hline Melón & 0.02876 & 0.01011 & 0.01183 & 0.01997 & 0.02544 & 0.01264 & 0.02234 & 0.05697 & 0.76092 & 0.66158 & 0.42293 & 6.67244 & & 14.83925 & 3.88732 & 25.71004 & 14.93062 & 18.84600 & 19.34800 & 20.57523 & 16.64550 & 9.06936 & 11.98893 \\
\hline Mostaza & & & & & & & & & & & & 0.10318 & & 0.09900 & 0.19250 & 0.06580 & 0.35203 & 0.68688 & 0.59280 & 0.18170 & 0.13490 & & 0.14900 \\
\hline Nabo & & & & & & & & & & & & 0.15700 & 0.26690 & 0.15642 & 0.12166 & 0.17640 & 0.55680 & 0.25454 & & 1.12995 & 0.30672 & 0.68484 & 0.56322 \\
\hline Napa & & & & & & & & & & & & 0.16646 & 0.21000 & 0.45000 & 0.41040 & 0.96900 & 0.67392 & 1.53090 & 0.66150 & 0.35280 & 0.70000 & 0.62928 & 0.28320 \\
\hline Naranja & & & & & & & & & & & & 2.50120 & & 2.80630 & 3.68161 & 4.65608 & 4.75000 & 7.16520 & 7.39453 & 8.20011 & 11.22473 & 11.44556 & 10.95637 \\
\hline Nopal & & & & & & & & & & & & & & 0.84525 & 0.82325 & 1.01270 & 1.11725 & 1.11540 & 1.13390 & 1.12547 & 1.23265 & 1.00280 & 1.16226 \\
\hline Olivo & & & & & & & & & & & & 0.07875 & & 0.18300 & 0.08400 & 0.13440 & 0.13776 & 0.14580 & 0.13937 & 0.13085 & & & \\
\hline Palma datilera & & & & & & & & & & & & & & 1.21285 & 3.49600 & 10.73500 & 11.04000 & 11.28810 & 11.77860 & 12.38445 & 15.71804 & 15.03020 & 15.53100 \\
\hline Palma hornato & & & & & & & & & & & & & & & & & 2.10000 & 2.52280 & 2.89000 & 3.49140 & 2.75835 & 2.50457 & 2.48625 \\
\hline Papa & & & & & & & & & & & & & & & & 0.02100 & 0.17280 & & & & & & \\
\hline Pastos forrajeros & & & & & & & & & & & & 0.03167 & & & & & & & & & & & \\
\hline Pepino & & & & & & & & & & & & 0.47211 & & & & 0.16772 & 0.30102 & 0.29784 & 0.44370 & 0.08550 & 0.64850 & 0.01950 & \\
\hline Perejil & & & & & & & & & & & & 0.16182 & 0.11293 & 0.53130 & 0.44000 & 0.61664 & & 2.46458 & 2.11600 & 5.19995 & 2.97390 & 2.44640 & 3.22056 \\
\hline Plantágo & & & & & & & & & & & & & & 0.00137 & & & 1.39932 & & & & & & \\
\hline Quelite & & & & & & & & & & & & 0.61360 & 0.36355 & 0.62580 & 0.15000 & 0.13900 & 0.61275 & 0.48825 & 0.85461 & 1.06920 & 1.34858 & 0.78390 & 0.95705 \\
\hline Rábano & 0.01292 & 0.01197 & 0.01284 & 0.05440 & 0.37126 & 0.27921 & 0.67312 & 0.74844 & 3.37273 & 4.90620 & 2.96985 & 3.27580 & 2.24049 & 10.81566 & 17.02170 & 35.11063 & 42.77128 & 36.91550 & 22.43073 & 17.22231 & 18.81625 & 10.56938 & 13.47121 \\
\hline Rapini & & & & & & & & & & & & 0.86724 & 0.78259 & 1.23690 & 2.05065 & 2.59700 & 3.41824 & 4.27180 & 2.57896 & 3.46000 & 1.16447 & 0.51600 & \\
\hline Remolacha & & & & & & & & & & & & & & & 0.10950 & 0.21680 & & & & & & & \\
\hline Ryegrass & 0.10246 & 0.10204 & 0.36009 & 0.46642 & 1.16460 & 0.99216 & 3.87063 & 8.93549 & 32.17147 & 18.17235 & 35.37216 & 50.59472 & 46.02543 & 47.55112 & 69.90462 & 58.76183 & 41.07062 & 52.23005 & 41.73624 & 33.15898 & 45.21280 & 47.73408 & 53.15356 \\
\hline Sandía & 0.03016 & 0.00795 & 0.01160 & 0.02390 & 0.97637 & 0.08030 & 0.04096 & 0.23296 & 0.56874 & 2.12604 & 0.83306 & 3.47194 & 0.34650 & 6.15430 & 4.17240 & 18.60270 & 38.47675 & 30.82800 & 28.47792 & 22.72160 & 15.90703 & 36.37938 & 50.59035 \\
\hline
\end{tabular}




\section{Cuadro 7. (Continuación)}

\begin{tabular}{|c|c|c|c|c|c|c|c|c|c|c|c|c|c|c|c|c|c|c|c|c|c|c|c|c|}
\hline & 1980 & 1981 & 1982 & 1983 & 1984 & 1985 & 1986 & 1987 & 1988 & 1989 & 1990 & 1991 & 1992 & 1993 & 1994 & 1995 & 1996 & 1997 & 1998 & 1999 & 2000 & 2001 & 2002 & 2003 \\
\hline Sorgo escobero & & & & & & & & & & & & & 5.85330 & & 13.44896 & 4.92800 & 0.72494 & 7.08000 & 2.06640 & 6.63000 & 2.32980 & 1.06860 & 1.21638 & \\
\hline Sorgo forrajero & 0.03951 & 0.07598 & 0.07316 & 0.06451 & 0.92018 & 1.91978 & 0.89671 & 3.00691 & 4.07904 & 4.79995 & 10.13402 & & 0.27200 & & 28.41696 & 39.59292 & 46.61125 & 171.52863 & 50.52738 & 106.55586 & 91.40862 & 96.52165 & 76.54465 & 61.83495 \\
\hline Sorgo grano & 0.00691 & 0.00606 & 0.00587 & 0.03321 & 0.06575 & 0.21298 & 2.91071 & 3.37275 & 1.40306 & 3.31310 & 3.34681 & & 5.47560 & & 5.62568 & 21.54656 & 59.61587 & 35.34357 & 20.97885 & 27.60758 & 19.28430 & 9.98580 & 24.56375 & 40.18128 \\
\hline Tomatillo & & & & & & & & & & & & & 0.56090 & 0.01200 & 0.81600 & 1.25045 & 3.48524 & 10.00140 & 4.34850 & 18.18248 & 22.17165 & 34.45654 & 37.16757 & 33.94165 \\
\hline Toronja & & & & & & & & & & & & & & & 0.40560 & 0.24480 & 0.34848 & 0.27383 & 0.44400 & 0.50384 & 0.60620 & 0.63330 & 0.43512 & 0.66795 \\
\hline Trigo & 0.93907 & 0.93738 & 2.51403 & 5.60306 & 9.42093 & 12.77184 & 23.51257 & 47.57304 & 75.35976 & 87.02008 & 131.21148 & & 202.61236 & 279.37200 & 305.05209 & 325.98232 & 526.91196 & 578.02830 & 539.32833 & 469.51079 & 609.81064 & 437.85366 & 442.31236 & 654.38520 \\
\hline Varios & & & & & & & & & & & & & 0.64131 & 1.28640 & 0.25730 & 0.15906 & 4.14110 & 3.70760 & 10.48838 & 23.50161 & 10.06036 & 14.97687 & 22.44860 & 16.40853 \\
\hline vid & 0.01975 & 0.04646 & 0.18870 & 0.39072 & 0.38104 & 0.48704 & 3.09335 & 4.65449 & 7.31685 & 4.00710 & 8.27903 & & 10.19203 & & 11.10148 & 7.60634 & 13.15135 & 10.01545 & 20.71600 & 16.79463 & 20.41866 & 17.26104 & 27.17152 & 30.25097 \\
\hline Zacate bermuda & & & & & & & & & & & & & & & 3.87314 & 43.83210 & & 18.50136 & 22.86542 & 15.82982 & 40.68918 & 31.72500 & 32.78678 & 66.11089 \\
\hline Zanahoria & 0.00189 & 0.00125 & 0.00074 & 0.01031 & 0.02687 & 0.02139 & 0.03990 & 0.03325 & 3.81360 & 6.98320 & 6.91539 & & 3.43454 & 3.52278 & 33.92000 & 10.92750 & 10.43460 & 13.60829 & 11.29064 & 11.46915 & 6.57280 & 3.09125 & 3.66345 & 4.47900 \\
\hline Total & 5.49734 & 4.48512 & 8.65726 & 18.73021 & 36.50411 & 51.46397 & 98.79179 & 247.58444 & 404.72409 & 428.54100 & 570.14324 & & 530.04038 & 410.81324 & 871.88643 & $1,457.56075$ & 2055770 & $3,103.106602$ & $2,440.63055$ & 2,321.14901 & $2,297.184632$ & $2,137.900832$ & $2,132.76715$ & $2,630.51660$ \\
\hline
\end{tabular}

\section{Fuente: Elaboración a partir de datos de Sagarpa.}

Nota: A partir de 1993 se recorrieron tres dígitos al peso mexicano para el manejo de cantidades de menor monto. En este cuadro, todas las cantidades anteriores a dicho año han sido ajustadas para hacer posible la comparación. 
Figura 9.

Valle de Mexicali: Tendencias de diversificación productiva

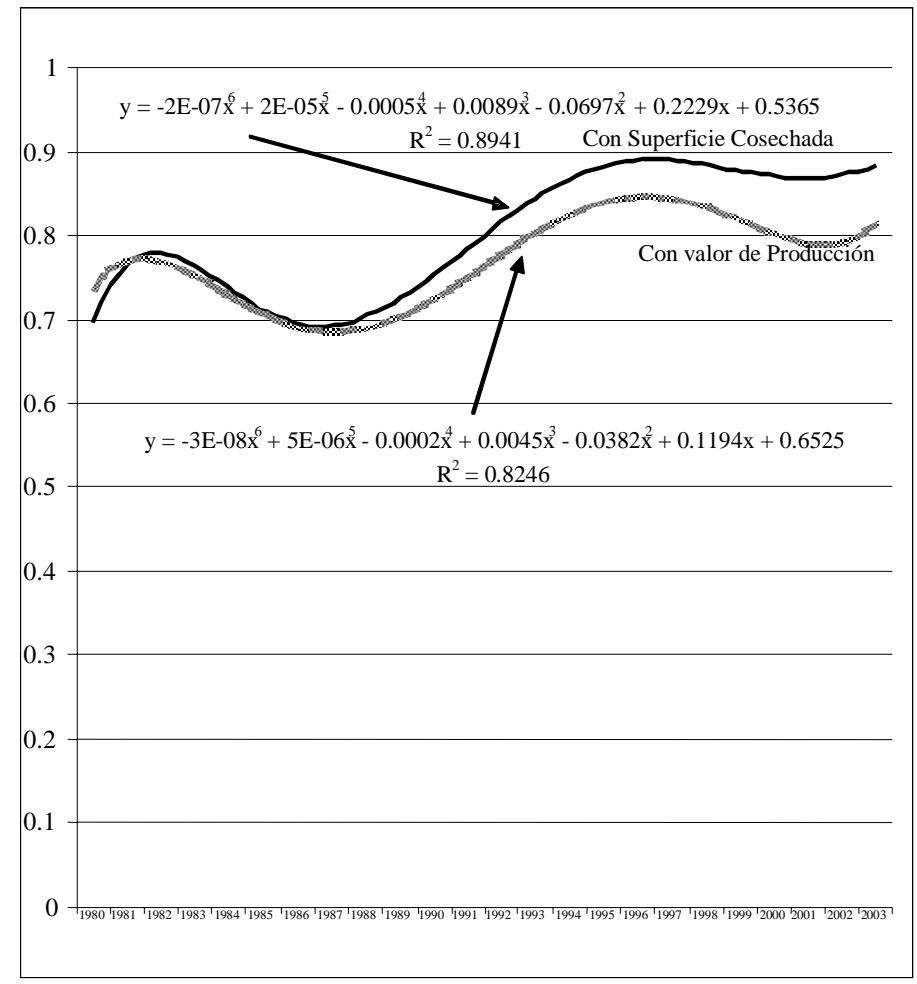

Fuente: Cuadro 8.

Lo anterior nos lleva a concluir que existen otros elementos que influyen de manera más determinante en la decisión del productor de sembrar tal o cual cultivo. En la lógica de mercado los precios serían la primera referencia, sin embargo, encontramos que los cultivos que concentran la mayor parte de la superficie en producción son a los que más castiga el mercado con bajos precios. De este modo, sin restarle importancia al nivel de precios, es fundamental buscar explicaciones adicionales a la decisión del productor, que pueden tener que ver con el mayor conocimiento sobre determinado cultivo, lo que funciona como reductor de incertidumbre. En otras palabras, los produc- 
Cuadro 8. Valle de Mexicali: Índice de concentración de Gini

\begin{tabular}{|c|c|c|c|c|c|}
\hline & $\begin{array}{c}\text { Con superficie } \\
\text { cosechada }\end{array}$ & $\begin{array}{l}\text { Con valor de } \\
\text { producción }\end{array}$ & & $\begin{array}{c}\text { Con superficie } \\
\text { cosechada }\end{array}$ & $\begin{array}{c}\text { Con valor de } \\
\text { producción }\end{array}$ \\
\hline 1980 & 0.711 & 0.744 & 1992 & 0.879 & 0.844 \\
\hline 1981 & 0.754 & 0.764 & 1993 & 0.891 & \\
\hline 1982 & 0.76 & 0.759 & 1994 & 0.862 & 0.814 \\
\hline 1983 & 0.764 & 0.773 & 1995 & 0.879 & 0.839 \\
\hline 1984 & 0.748 & 0.721 & 1996 & 0.869 & 0.852 \\
\hline 1985 & 0.725 & 0.701 & 1997 & 0.878 & 0.85 \\
\hline 1986 & 0.713 & 0.685 & 1998 & 0.879 & 0.825 \\
\hline 1987 & 0.706 & 0.739 & 1999 & 0.87 & 0.806 \\
\hline 1988 & 0.714 & 0.702 & 2000 & 0.884 & 0.811 \\
\hline 1989 & 0.673 & 0.656 & 2001 & 0.879 & 0.796 \\
\hline 1990 & 0.689 & 0.675 & 2002 & 0.872 & 0.802 \\
\hline 1991 & & & 2003 & 0.878 & 0.808 \\
\hline
\end{tabular}

Fuente: Elaboración a partir de cuadro 1 y 7.

tores trigueros, algodoneros y alfalferos, por mencionar los más numerosos, no se aventuran fácilmente a la siembra de un cultivo que no conocen y prefieren continuar con lo que saben.

\section{Conclusiones: estancamiento y desaliento de la actividad agrícola regional}

Los resultados obtenidos del análisis hasta aquí elaborado sobre la evolución productiva de la región sostienen la hipótesis inicial, que califica las condiciones de la actividad agrícola regional como de estancamiento y desaliento. Las siguientes recapitulaciones condensan el comportamiento negativo identificado:

- La superficie cosechada tiene una tendencia ligera a la baja, lo queconfirmala dismi nución relativamentelenta pero persistente de la frontera agrícola.

- Los rendimientos físicos de los principales cultivos observan un comportamiento relativamente diferenciado, mientras que el trigo presenta un incremento modesto, el algodón parece 
haber encontrado el límite de su productividad al observar un comportamiento similar durante los años observados. Es importante considerar la afectación por plagas que en años específicos han afectado a estos cultivos y que ha generado comportamientos atípicos en sus indicadores productivos.

- El volumen deproducción resulta preocupante. El achicamiento de la frontera agrícola y el escaso comportamiento al alza delos rendimientos físicos colocan a la producción agrícola en una delicada perspectiva negativa.

- Los rendimientos económicos son dramáticamente regresivos, con excepción del cebollín y el espárrago, los cuales conservan rendimientos erráticos pero final mente aceptables. Los cultivos tradicionales y masivos resultan en una declinación del rendimiento económico dela tierra.

- El valor de la producción también presenta una tendencia a la reducción. Aun cuando en algunos años se incrementa, finalmente su comportamiento histórico resulta menor, tanto en términos absolutos como relativos.

- La diversificación productiva resulta negativa. A pesar de que se observa un mayor número de cultivos, la concentración de la actividad en unos pocos hace que, en lugar de disminuir, la especialización agrícola dela región se incremente.

\section{Bibliografía}

Aguirre Jaime, A. (1994), Introducción al tratamiento de series temporales. A plicación a las ciencias de la salud, Díaz de Santos, Madrid. Arellano, M. (2001), Introducción al análisis clásico de series de tiempo, 5campus.com, Estadística, www.5campus.com/ leccion/ seriest> Bancomer (1976), La economía del estado de Baja California N orte, Sistema de Bancos de Comercio-Baja Cal ifornia N orte, Colección de Estudios Económicos Regionales, México.

Bassols Batalla, A . (1980), G eografía económica de M éxico. Teoría, fenómenos generales, análisis regional, Cuarta edición, Trillas, M éxico.

Calva, J. L. (2000), M éxico más allá del N eoliberalismo. 0 pciones dentro del cambio global, Plaza y Janés, México. 
Coplade-B.C. (1990), “Desarrollo económico del campo”, Plan Estatal deD esarrollo 1990-1995, Baja Cal ifonia, México.

Cortés, F. y R. M. Rubal cava (1984), Técnicas estadísticas para el estudio dela desigual dad social, El Colegio de México, México.

Díaz, C.H., S.L. Jiménez, R.J. Laird y F.A. Turrent (1999), El Plan Puebla 1967-1992. A nálisis de una estrategia de desarrollo agrícola de la agricultura tradicional, Colegio de Postgraduados, México.

Eicher, C. K. y J. M. Staatz (comps.) (1991), D esarrollo agrícola en el tercer mundo, Textos de Economía, Fondo de Cultura Económica, primera edición en español, México.

Grijalva, A. (1978), El desarrollo del capitalismo en el Valle de M exicali, Facultad Latinoamericana de Ciencias Sociales (FLACSO), México.

Jiménez Sánchez, L. (1999), N otas de clase en el Seminario de Estrategias para el D esarrollo A grícola R egional, Programa de Doctorado en Estrategias para el Desarrollo A grícola Regional, Colegio de Postgraduados, Campus Puebla, M éxico.

Márquez de Romero, M. C. y R. Romero (1987), G eografía e historia de Baja California, Costa-Amic, México.

Pérez Espejo, R. (1988), “Principales características de la agricultura en los estados fronterizos", en Estudios Fronterizos, UABC, vol. III, núm. 9.

Poder Legislativo de B.C. (2002), A nálisis del presupuesto agropecuario, Comisión deA gricultura, Ganadería y Pesca dela XVII Legislatura deBaja California, México.

Rechy Montiel, M. (2000), La política agrícola en M éxico, Debora Publicaciones, México.

SARH (1976), 0 bras derehabilitación del distrito de riego num. 14-Río Colorado, Baja California y Sonora, Dirección General de Irrigación y Control de Ríos, México.

SEFOA (1991), D iagnóstico de la producción y comercialización agrícola del estado de Baja California, Mexicali, B.C., México.

Vernon W., R. y Y. Hayami (1989), D esarrollo agrícola. U na perspectiva internacional, Fondo de Cultura Económica, México. 